\title{
Research Paper \\ Designing COROOR Computer-Based Cognitive Rehabilitation Program and Investigating its Effect on Spelling Efficacy and Visual-Phonological Processing in Students with Dyslexia - Dysorthographia
}

\author{
Mahshad Motaghedifard ${ }^{* 1}$, Fereshteh Baezzat ${ }^{2}$, Vahid Nejati ${ }^{3}$, Habibollah Naderi ${ }^{4}$ \\ 1. Ph.D. in Educational Psychology, Faculty of Humanities and Social Sciences, University of Mazandaran, Babolsar, Iran \\ 2. Associate Professor, Department of Psychology, Faculty of Humanities and Social Sciences, University of Mazandaran, Babolsar, \\ Iran \\ 3. Associate Professor, Department of Psychology, Faculty of Education and Psychology, Shahid Beheshti University, Tehran, Iran \\ 4. Assistant Professor, Department of Psychology, Faculty of Humanities and Social Sciences, University of Mazandaran, Babolsar, \\ Iran \\ Citation: Motaghedifard M, Baezzat F, Nejati V, Naderi H. Designing \\ coroor computer-based cognitive rehabilitation program and \\ investigating its effect on spelling efficacy and visual-phonological \\ processing in students with dyslexia - dysorthographia. J Child Ment \\ Health. 2021; 7(4): 264-283.
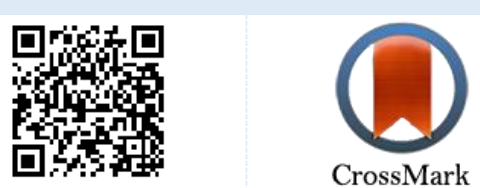 \\ do $10.52547 / \mathrm{jcmh} \cdot 7.4 .17$ \\ URL: http://childmentalhealth.ir/article-1-850-en.html \\ 0.1001.1.24233552.1399.7.4.10.8
}

\section{A R T I C L E I N F O}

Keywords:

Spelling efficacy, visual-phonological processing, students with dyslexia dysorthographia, COROOR computerbased cognitive rehabilitation

Received: 26 Jun 2019

Accepted: 15 Sep 2020

Available: 17 Mar 2021

\section{A B S T R A C T}

Background and Purpose: Weakness of students with dyslexia-dysorthographia in encoding, storage, and retrieval of phonetic writing system leads to the high importance of creating and implementing effective interventional programs in the field of specific learning disabilities. So, the aim of the present study was designing COROOR (Cognitive Rehabilitation of Orthography \& Reading) computer-based cognitive rehabilitation program and investigating its effect on spelling efficacy and visual-phonological processing in the students with dyslexia - dysorthographia.

Method: This research was a quasi-experimental study with pretest-posttest control group design and a three-month follow-up period. The population consisted of all third grade primary school boy students with dyslexia-dysorthographia who had referred to learning disabilities centers in Kashan city in the academic year 2018-2019. Among them, 20 students with dyslexia-dysorthographia based on diagnostic tests (Dyslexia syndromes checklist based on DSM-5 criteria, Wechsler Intelligence Scale for Children (WISC), and Conners Rating Scale) were selected by purposive sampling and then, randomly assigned to either the experimental or the control group (10 per group). After implementing the pretests of writing expression disorder (spelling component) (Baezzat, 2010) and visual-phonological processing (Hosaini, Moradi, Kormi Nouri, Hassani, \& Parhoon, 2016), the experimental group received the COROOR computer-based cognitive rehabilitation program, while the control group underwent no intervention. Immediately after the intervention, post-tests were performed on both groups. After three months, follow-up tests were performed on the groups. The data were analyzed using repeated measures multiple-analysis of variance.

Results: Findings showed that 20 sessions of cognitive rehabilitation for orthographic and color detection tasks by COROOR software reduced spelling errors and improved visual-phonological processing in the experimental group at post-test and follow-up stages $(p<0.01)$

Conclusion: According to the results, it can be said that the use of orthographic and color detection tasks by COROOR computer-based cognitive rehabilitation is effective for the spelling and visualphonological processing of students with dyslexia and dysorthographia. As a result, it can be recommended as a useful rehabilitation method to specialists and therapists in the field of specific learning disabilities.

* Corresponding author: Mahshad Motaghedifard, Ph.D. in Educational Psychology, Faculty of Humanities and Social Sciences, University of Mazandaran, Babolsar, Iran.

E-mail: Mahshad_mf@yahoo.com

Tel: (+98) 1135303000

2476-5740/ @ 2021 The Authors. This is an open access article under the CC BY-NC-ND license

(https://creativecommons.org/licenses/by-nc-nd/4.0/). 


\section{Extended Abstract}

\section{Introduction}

Dyslexia-Dysorthographia is among the most essential problems faced by children with specific learning disabilities. It is mainly characterized by a lack of progress in reading accuracy, speed and comprehension, difficulty in spelling, recognition, and poor decoding (2). People with dyslexiadysorthographia have difficulty in remembering the word dictation and word manipulation which requires the maintenance of changing phonological information (7).

Another neuropsychological characteristic related to the high percentage of visio- auditory learning is visual-phonological processing. Delays in visioauditory perception will cause certain cognitive impairment (5). Researchers such as De Luca, Burani, Paizi, Spinelli and Zoccolotti (9) and Romani, Tsouknida, di Betta and Olson (10) in the diagnosis of dyslexia-dysorthographia emphasized the multi-element (i.e. visual-spatial, phonological, and other) processing deficits.

The idea of phonological processing is based on this fact that during the acquisition and comprehension of spoken and written codes, language sounds are stored and retrieved in the form of three skills: phonological awareness, phonological working memory, and quick automatic naming (13). In this regard, the studies showed that the reading and spelling in students with dyslexia are affected by poor phonological awareness (15). Furthermore, people with impaired phonological working memory cannot remember or visualize the letters and letter order of words (16). Besides, based on the results, word recognition process in the people with dyslexiadysorthographia is weak. Incomplete lexical representations and low processing speed reflect the lack of automatic word recognition $(12,18,19)$.

Cognitive rehabilitation is a therapeutic approach that involves producing educational software as new learning opportunities for students with dyslexiadysorthographia. Based on Thurman and Takala (23) and Mahler, Joerns, and Schuchardt (24), cognitive rehabilitation exercises reduce the symptoms of dyslexia and dysorthographia in students. In a study with the phonological awareness exercises, Baezzat,
Moradi and Motaghedifard (15) enhanced the auditory memory in children with dysorthographia. According to Dahlin (26), Perbuma, Peeters, Overvelde, Nijhuis-van der Sanden and Steenbergen (27), and Chaco, Uderman, Feirsen, Bedard and Marks (28), working memory training increases memory capacity by targeting the storage and manipulating the verbal and non-verbal components of the working memory.

No study has yet aimed to reinforce the three skills of phonological awareness, phonological working memory, and rapid automatized naming based on the phonological processing in individuals with a disorder; hence, the present study was conducted to design COROOR computer-based cognitive rehabilitation program and to investigate its effect on the efficiency of spelling and visual-phonological processing in students with dyslexia- dysorthographia.

\section{Method}

This research was a quasi-experimental study with pretest-posttest control group design and follow-up period. The population consisted of all third grade primary school boy students with dyslexiadysorthographia who had referred to learning disabilities clinics in Kashan city in the academic year 2018-2019. Dyslexia-dysorthographia was diagnosed by Screening Inventory Reading Test of Shafiei etal. (31), Wechsler Intelligence Scale for Children (WISC) (standardized by Shahim) (32), and Conners Rating Scale (Parent Short Form) (33). The sample individuals were selected by purposive sampling and then, randomly assigned to either the experimental or the control group (10 per group). Then, both groups underwent the pretest, including Baezzat's writing expression disorder (spelling components) (35) and visual-phonological processing of Hosaini etal. (36).After that, the experimental group received 20 group training sessions on COROOR rehabilitation software $(60 \mathrm{~min}$ per session). COROOR rehabilitation software was designed by Motaghedifard under the supervision of Baezzat and Nejati in cooperation with the Neuroscience Research Center of Shahid Beheshti University of Tehran in 2019, modeled on Dybuster software (30). This software is based on three parts, of which the spelling task and color detection task 
were used in this research. COROOR computerbased cognitive rehabilitation consists of three parts: graph task, orthographic task and color detection task. The orthography task is related to strengthening phonological awareness and improving orthography through phonological and visual working memory. Exercises of the color detection task strengthen the ability of rapid automatized naming by rapidly naming the visual stimulus of letters and colors as part of the variance of the ability to recognize the words. Intervention sessions were held three times a week in one of the centers of learning disabilities in Kashan. Immediately after the intervention period, spelling and visual-phonological processing posttests were performed on both groups. To evaluate the effects of exercise stability, the relevant post-tests were performed again on both groups three months after the intervention. Finally, data analysis was performed using multivariate analysis of variance with repeated measures.

\section{Results}

First, the descriptive statistics of the study were investigated, and then the assumptions and multivariate analysis of variance with repeated measures were presented.

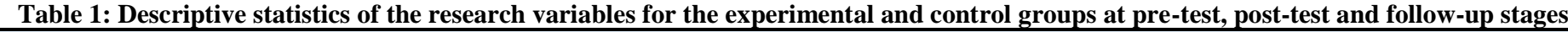

\begin{tabular}{|c|c|c|c|c|c|c|}
\hline variable & & oup & $\mathbf{M}$ & SD & Shapiro-Wilkes test & sig \\
\hline \multirow{6}{*}{ Spelling } & \multirow{2}{*}{ Pre-test } & experimental & 54.50 & 9.52 & .98 & .98 \\
\hline & & control & 57.60 & 2.63 & .90 & .26 \\
\hline & \multirow{2}{*}{ Post-test } & experimental & 25.50 & 14.05 & .88 & .32 \\
\hline & & control & 58.10 & 4.01 & .86 & .08 \\
\hline & \multirow{2}{*}{ follow-up } & experimental & 16.80 & 9.35 & .89 & .06 \\
\hline & & control & 51.20 & 3.31 & .97 & .94 \\
\hline \multirow{6}{*}{ visual-phonological processing } & \multirow{2}{*}{ Pre-test } & experimental & 259.10 & 20 & .90 & .25 \\
\hline & & control & 213.20 & 21.16 & .89 & .16 \\
\hline & \multirow{2}{*}{ Post-test } & experimental & 332.20 & 27.43 & .95 & .69 \\
\hline & & control & 246.30 & 43.50 & .96 & .84 \\
\hline & \multirow{2}{*}{ follow-up } & experimental & 334.60 & 27.20 & .95 & .70 \\
\hline & & control & 245.40 & 69.25 & .88 & .13 \\
\hline
\end{tabular}

The results of Table 1 showed that the mean and standard deviation of the groups in the pre-test stage were close to each other; however, in the post-test and follow-up stages, the experimental groups experienced higher variance compared to the control group.

Table 2: Results of the within and between subjects analysis of variance

\begin{tabular}{|c|c|c|c|c|c|c|}
\hline Source of variation & sum of squares & df & mean sum of squares & $\mathbf{F}$ & sig & partial eta squared \\
\hline \multicolumn{7}{|c|}{ within subjects } \\
\hline time & 4862.02 & 1 & 4862.02 & 62.01 & 0.00 & 0.77 \\
\hline time $*$ group & 2449.22 & & 2449.22 & 31.23 & 0.00 & 0.63 \\
\hline error & 1411.25 & 18 & 78.40 & & & \\
\hline \multicolumn{7}{|c|}{ between subjects } \\
\hline group & 10375.35 & 1 & 10375.35 & 62.97 & 0.00 & 0.77 \\
\hline error & 2965.63 & 18 & 164.75 & & & \\
\hline
\end{tabular}

Based on the findings of Table 2, the difference between spelling scores in the three stages of the study was significant $(\mathrm{p}<0.01)$. The mean scores in the experimental and control groups were significantly different $(\mathrm{p}<0.01)$. In addition, the interaction between research stages and group membership was significant $(\mathrm{p}<0.01)$. Therefore, the experimental and control groups were significantly different in terms of mean spelling score at pre-test, post-test and follow-up stages. 
Table 3: Results of the within and between subjects analysis of variance

\begin{tabular}{|c|c|c|c|c|c|c|}
\hline Source & sum of squares & df & mean square & $\mathbf{F}$ & sig & partial eta squared \\
\hline \multicolumn{7}{|c|}{ within subjects } \\
\hline time & 77176.22 & 1 & 77176.22 & 52.33 & 0.00 & 0.74 \\
\hline time $*$ group & 30969.22 & & 30969.22 & 21 & 0.00 & 0.53 \\
\hline error & 26543.05 & 18 & 1474.61 & & & \\
\hline \multicolumn{7}{|c|}{ between subjects } \\
\hline group & 176258.40 & 1 & 176258.40 & 79.37 & 0.00 & 0.81 \\
\hline error & 39369.26 & 18 & 2220.51 & & & \\
\hline
\end{tabular}

According to the findings of Table 3 , the difference between the scores of phonological-visual processing in the study stages was significant $(\mathrm{p}<0.01)$. The mean scores in the two groups were significantly different $(p<0.01)$. In addition, the interaction between research stages and group membership was significant $(\mathrm{p}<0.01)$. Therefore, the experimental and control groups were significantly different in terms of mean score at pre-test, post-test and followup stages.

\section{Conclusion}

Dyslexia-dysorthographia is a type of specific learning disabilities which causes problems in reading and spelling accuracy (1-3). In fact, phonological and writing representation, storage, and retrieval play a very important role in learning the correct spelling of words and are used in the orthography task of COROOR software. Consistent to the results obtained here, Hassanabadi et al. (16) identified the problems with orthography as difficulties in identifying, storing, and retrieving visual information, and by applying the task-process approach provided an opportunity to reduce the dictation errors by strengthening students' visual memory. In other consistent studies (26-28) working memory training by targeting two important memory factors, including storage and manipulation of verbal and non-verbal working memory, led to spelling efficiency. Therefore, the results of above-mentioned studies demonstrated the effectiveness of exercises designed to reduce spelling errors in students of the experimental group.

Findings also showed that after treatment and follow-up, the visual-phonological processing scores of the experimental group significantly changed compared to the control group. Thus, the special exercises of COROOR software were effective in increasing the visual-phonological processing scores of the experimental group. Theorists who emphasize the causal role of multi-element processing deficit in the occurrence of dyslexia-dysorthographia and diagnose the disorder on the basis of weakness in visual-phonological processing $(9,10)$ believe that students with dyslexia-dysorthographia can change their sensory processing with rehabilitation. This study aimed to provide coordination in visual and auditory processing by providing exercises in the orthography section of the software.

Through matching the sounds with their written forms and by visual-auditory storage of the spoken and written materials in the short-term and working memory, the students could process the alphabetic principles in the direction of orthography. In fact, the form of phonological visual connections between written words and their spoken counterparts in the memory is the basis of fast and correct word recognition (23-25) which was the focus of the orthography tasks of the software. In a study relatively consistent to the present findings, Hassanabadi et al. (16) and Mahler et al. (24) showed that if the rehabilitation of visual and auditory working memory leads to the higher performance in spelling tasks, especially the homophones, the visual and phonological processing will also improve.

Due to the ease of using cognitive rehabilitation programs and their attractiveness for children, it is suggested to provide the students with these programs as a part of school curriculum. In this study, the control group was evaluated only at the pre-test, post-test, and follow-up stages; hence, it is possible that the resulting changes have been due to factors other than software program. Future researchers are suggested to use an active control group. For example, activities unrelated to the aimed 


\section{Quarterly Journal of Child Mental Health}

Vol. 7, No. 4, Winter 2021

cognitive activity may be used, including puzzle completion, physical activities, and computer games.

\section{Ethical Considerations}

Following the research ethical principles: The license for conducting this study on the sample, bearing No. 1769/287580/650 dated 06 March 2018, was issued by Kashan Education Department. Also in this research, other ethical considerations such as written and complete consent of the sample and the principle of confidentiality have been observed. Funding: This study was conducted without sponsor and in the form of a doctoral dissertation.
Authors' contribution: This research is taken from the Ph.D. thesis of Ms. Mahshad Motaghedifard in the field of educational psychology at Mazandaran University. The first author was the senior researcher, the second author was the supervisor, and the third and fourth authors were the advisors. Conflict of interest: This research did not lead to any conflict of interest and the results are reported in a completely transparent manner.

Acknowledgments: We would like to thank the authorities of the Education Department, the administrative staff and educators of the Center for Learning Disabilities, and the participating children who cooperated with us in the best way during the present study. 


\title{
طراحى برنامه توانبخشى شناختى سرور مبتنى بر رايانه و بروسى تأثير آن بر كارآمدى هجى كردن و يردازش

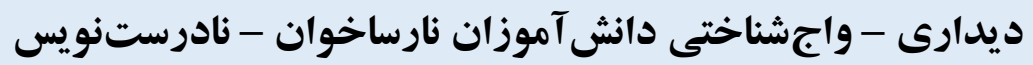

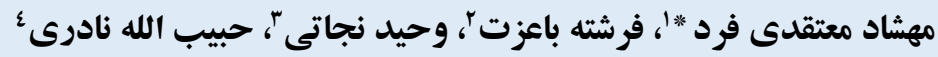

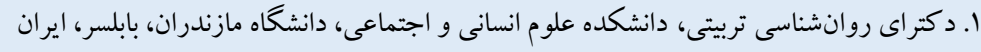

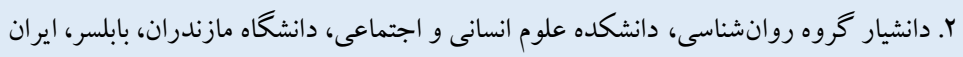

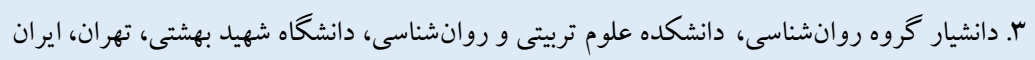

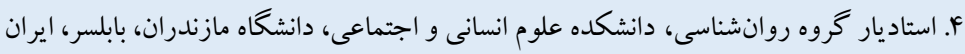

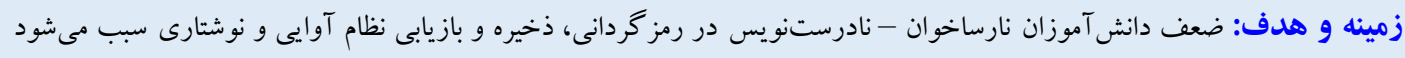

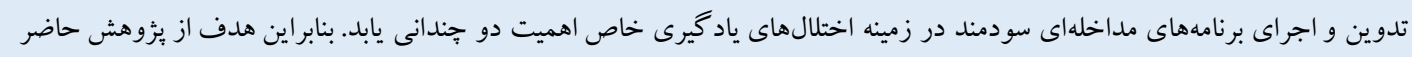

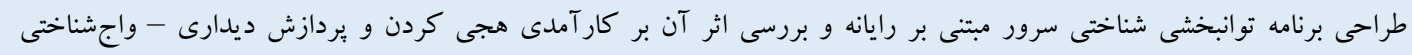

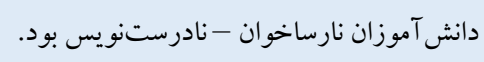

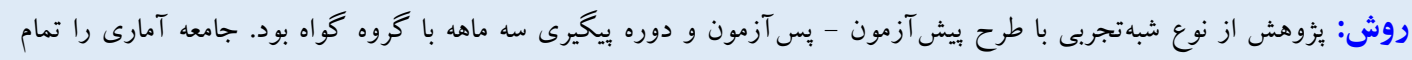

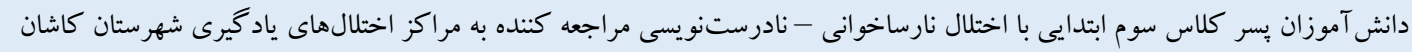
مشخصات مقاله

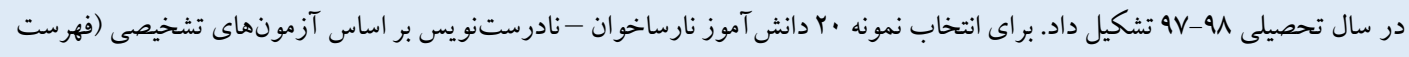

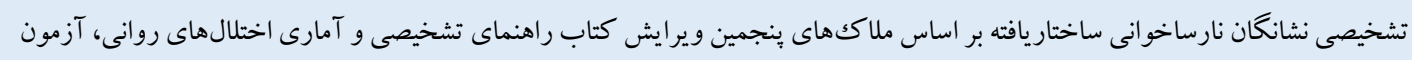

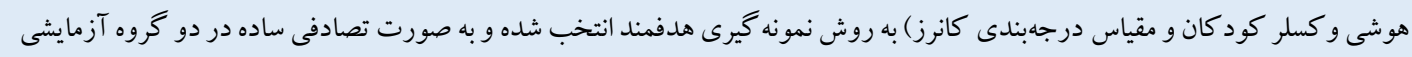

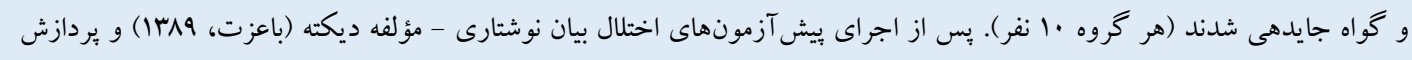

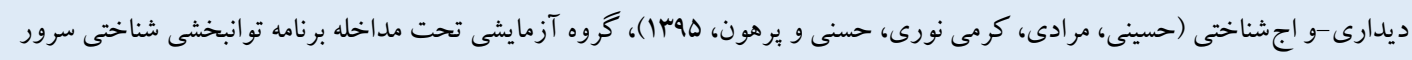

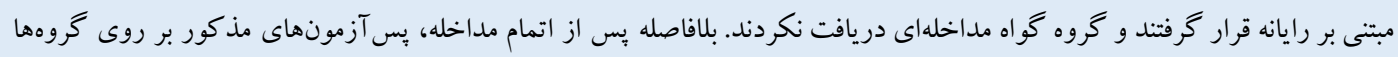

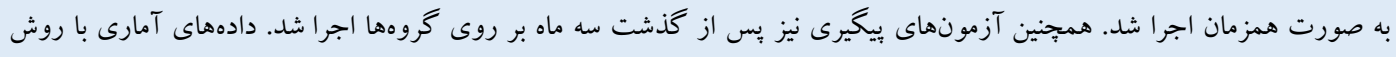

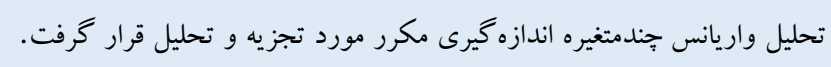

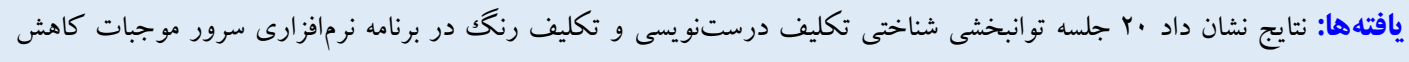

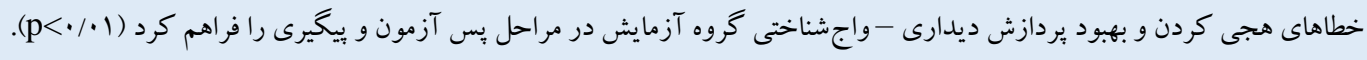

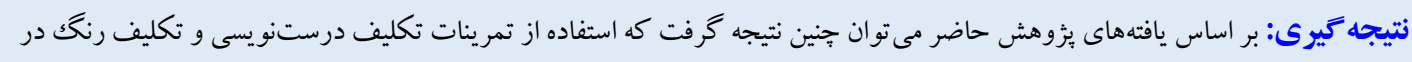

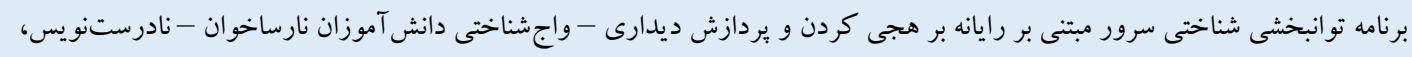

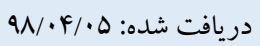

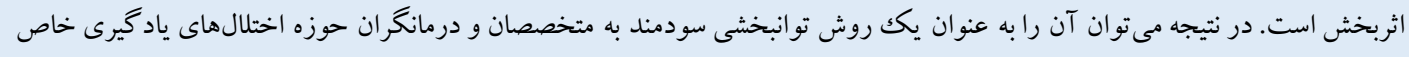

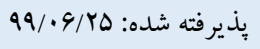


شــيدارى جهت دسـترسـى معنايى لغت ذخيره مىشـود. در مرحله

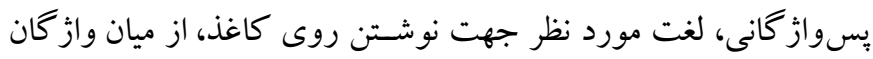

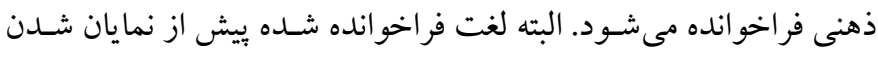
در دستـخط به طور موقت در حافظه فعال ديدارى - شــيدارى ذخيره مى ماند. افراد نارسـاخوان - نادرستـنويس با حافظه فعال ضعيف، در به

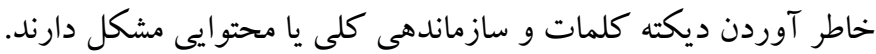

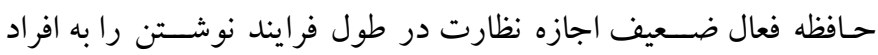

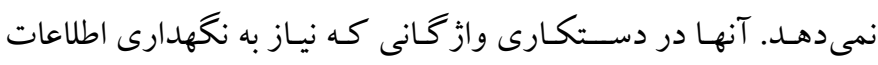

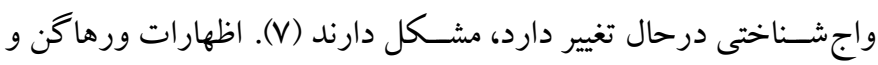

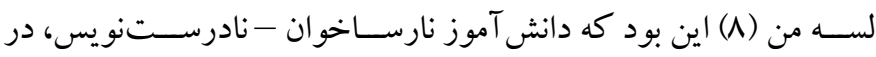

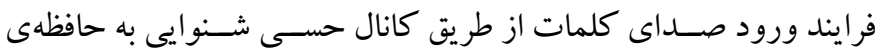

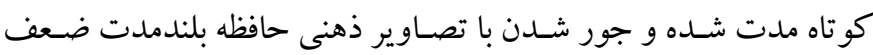
دارند. بسيارى از متخصصان از جمله وست وود (ه) معتقد بود بين خواندن و هجى كردن (درســتنويسـى)، ارتبـاط خيلى نزديكى وجود دارد وارد.

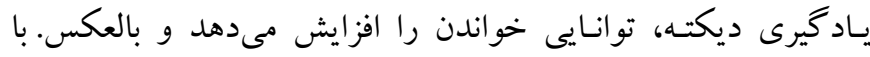

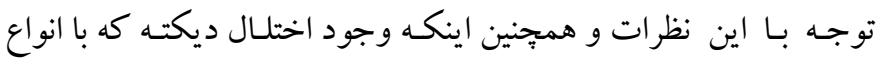

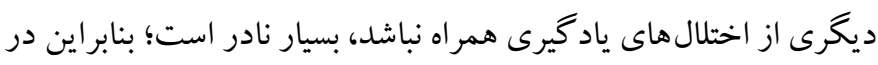

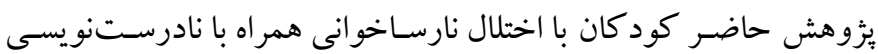

$$
\text { مورد بررسى قرار گرفت. }
$$

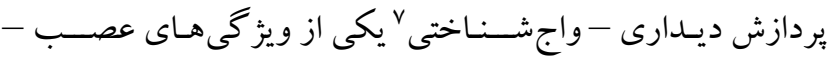
روانشــاختى اسـت كه نقش عمدهاى در ياد گيرى تحصـيلى ^ دارد و

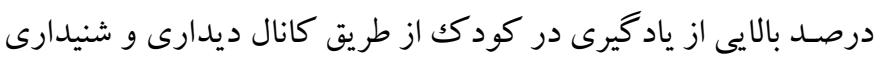

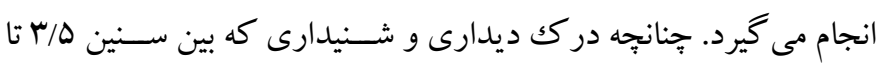

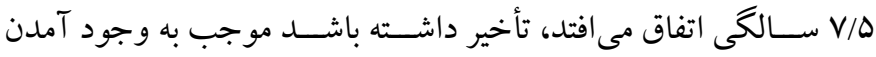

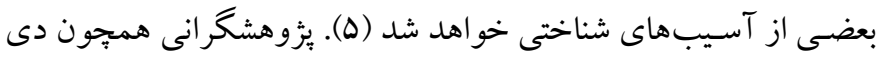

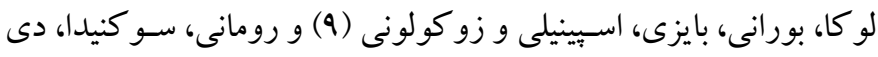

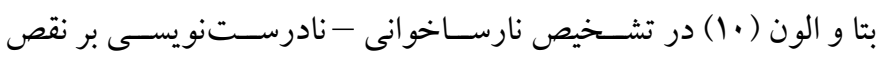

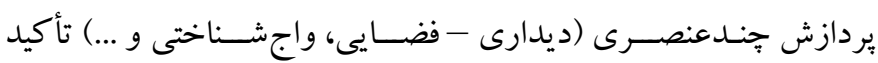

\section{Decoding}

6. Chronological age

7. Visual- phonological processing

8. Academic learning
مقدمه

اختلالهاى ياد گيرى خاص ' يكى از كشاكشبر انخيز ترين مسائلى است

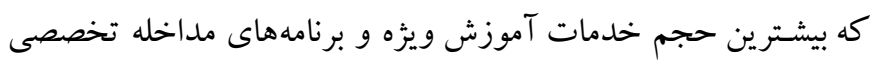
را به خود اختصاص مىدهد و آسيبهاى زيانبار اين اختلالها، فقط به حيطه عملكرد تحصيلى محدود نمى شود، كه ابعاد مختلف زند گیى فرده،

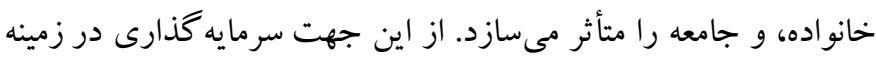

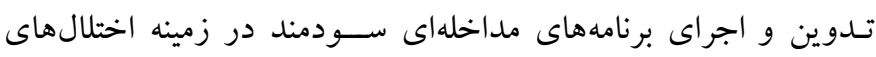
ياد گيرى خاص اهميت دوجندانى مى يابد (1).

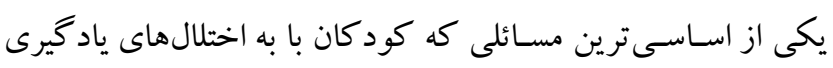

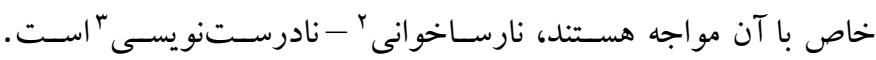

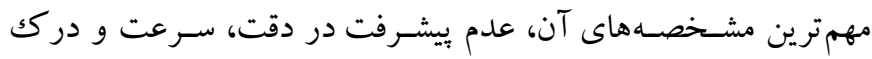

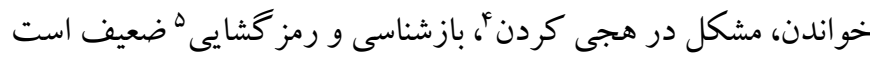

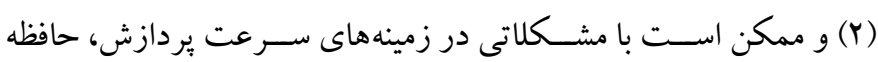

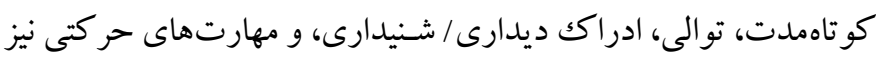
همراه باشـد (r). ضعف در برقرارى رابطه بين حروف و صداها، اختلال در تشـخيص كلمات شـبيه به هم، حدس زدن كلمات با در نظر كرفتن

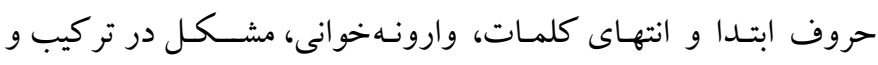

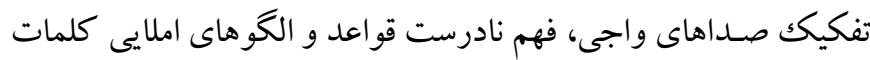

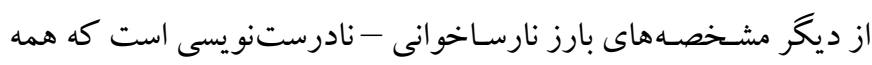

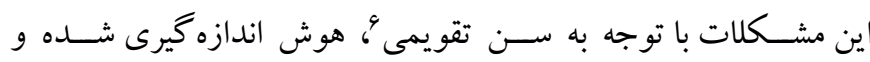

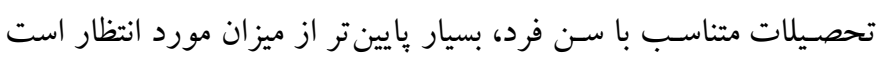

از ديدكاه برخى متخصـصــان از جمله وســت وود (ه) ارزيابى اين

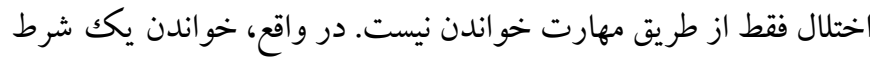
لازم اسـت، اما شـرط كافى نيست. هجى كردن (درستنويسى) به عنوان

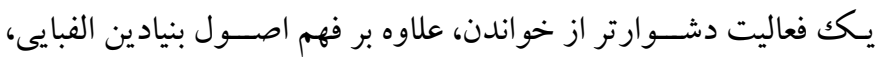

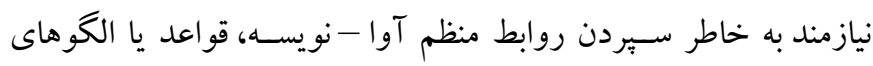
املايى اسـت (9) و يكك فرايند جندين مرحلهاى اسـتـ. مرحله يِيش واز كانى اولين مرحله بردازش شــناختى هجى كردن اسـت كه محر كى

1. Specific learning disorder

2. Dyslexia

3. Dysortographia

4. Spelling 
مؤلفه ديخر، حافظه فعال واجى است كه به رمز گردانى اطلاعات موقع

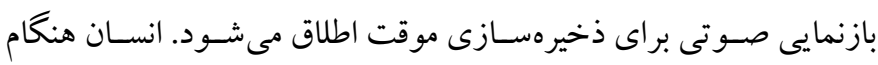

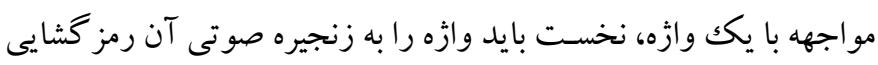

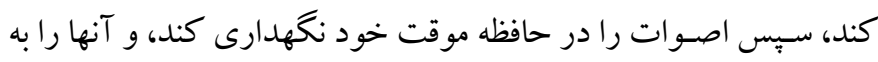

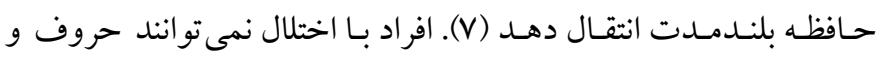

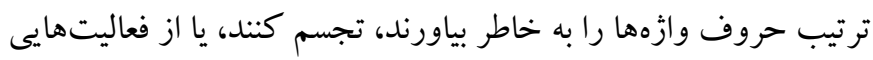
براى كمكك به تحكيم و تقويت حافظه ديدارى براى نوشــتن وازهها

$$
\text { استفاده نمى كنند (19). }
$$

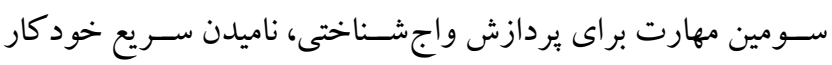

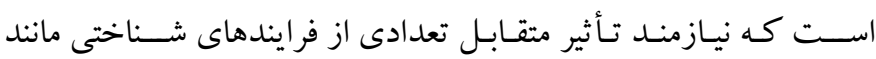

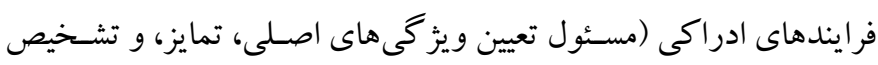

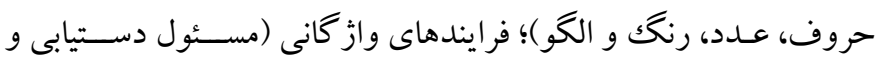

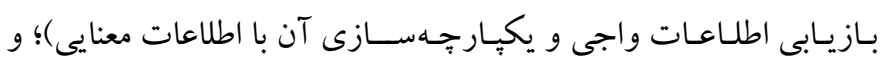

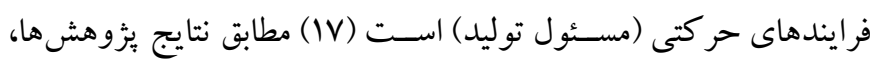

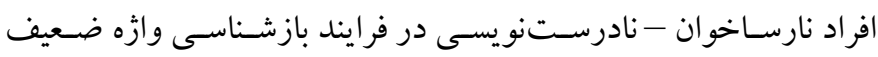
هستـند و اين مشكل دليلى است براى مشكلات در كك كردن در سطوح

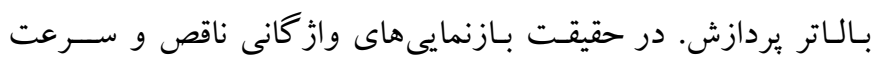
يردازش بايين منعكس كننده خود كار نبودن بازشـاسى وازمهاست (Y (I).

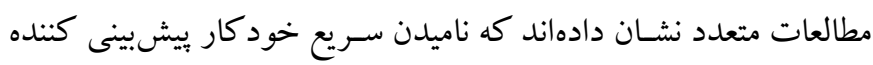
خواندن در همه زبانهاست و رابطه بين اين دو مهارت را به دامنه عوامل

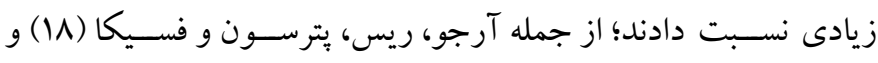

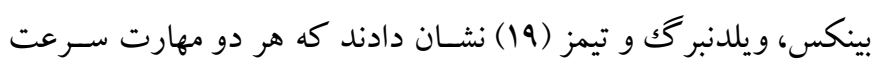

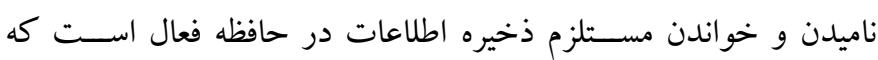

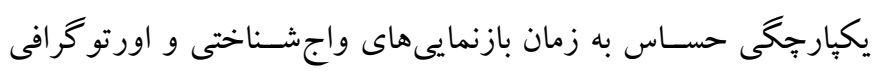

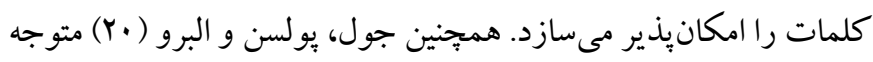

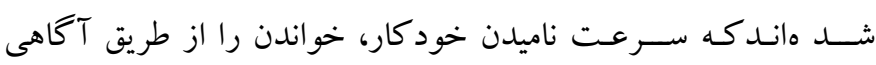
واجشناختى و بردازش اورتو گر افى بيشبينى مي كند.

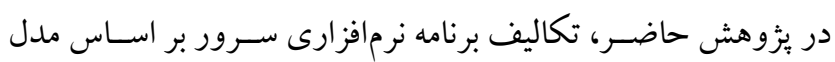

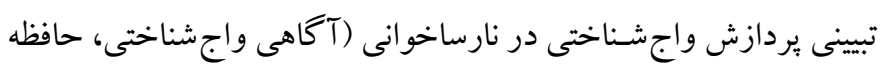

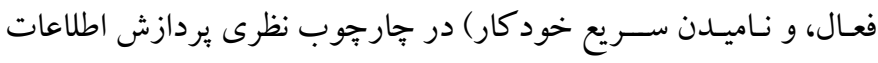

3. Phonological working memory

4. Rapid automatized naming
داشـتند. للازم به ذكر است تاكنون در يُزوهش هاى داخل كشور، متغيرى

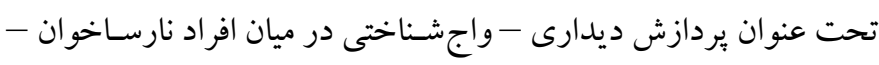

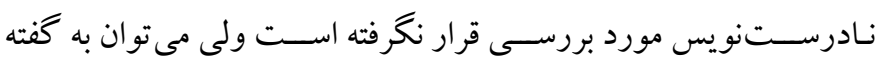

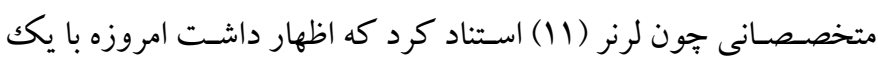

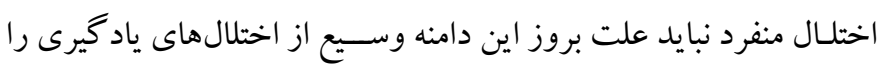

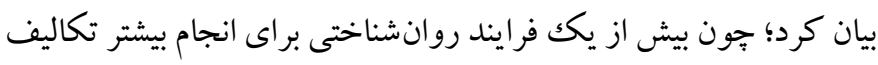

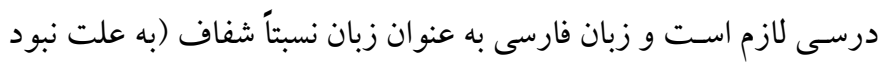

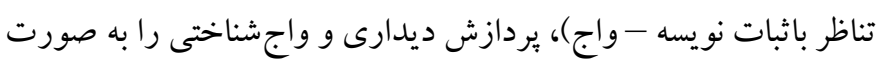

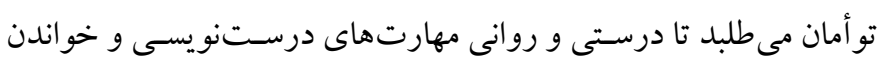

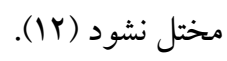

متخصصـان با توجه به مشكلات عمده دانش آموزان نارساخوان در

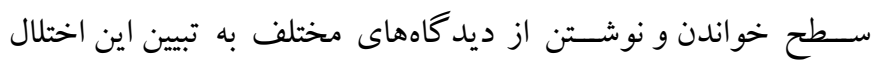

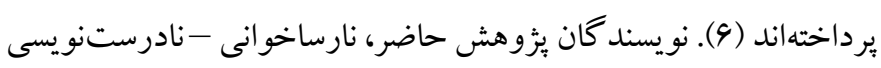

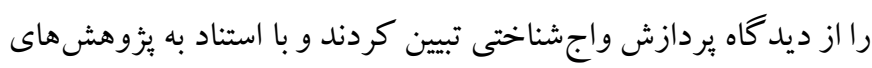

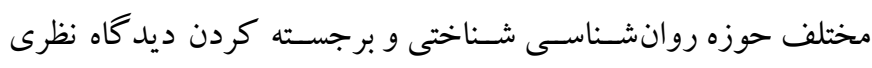

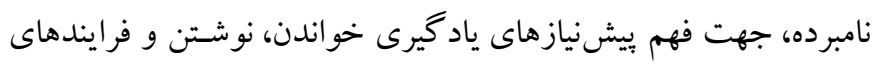

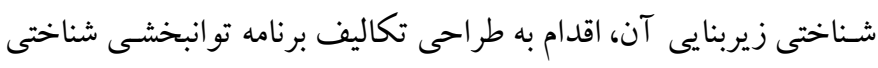

$$
\text { سرور' مبتنى بر رايانه كردند. }
$$

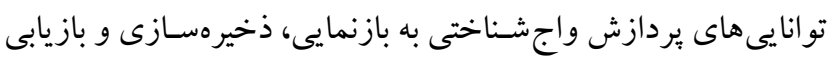

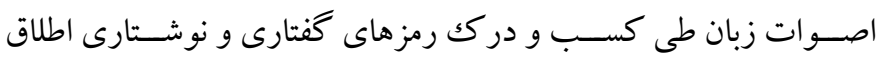

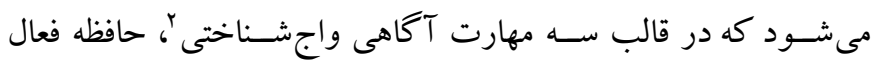

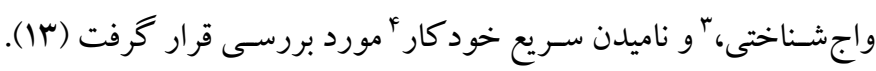

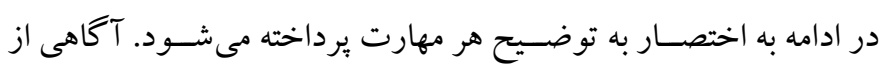

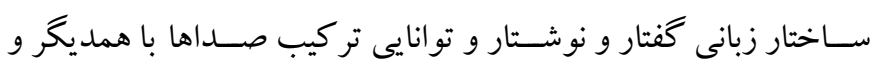

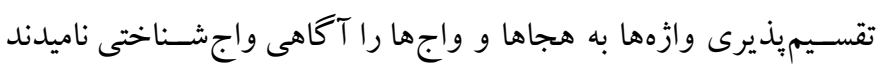

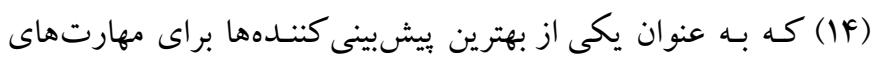

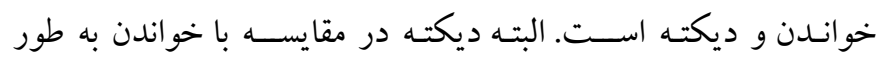
جدى ترى در اثر ضسعف واجشـناختى آسـيب مىبيند؛ زيرا دانش آموز

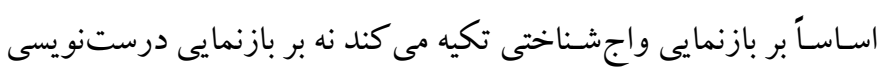

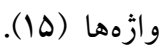

1. COgnitive Rehabilitation Of Orthography \& Reading (COROOR) 2. Phonological awareness 
فر انسـوى و در سـه نسـخه خانكى، كلينيكى و مدرسـهاى موجود اسـت.

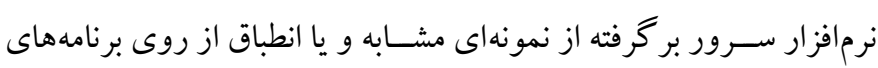

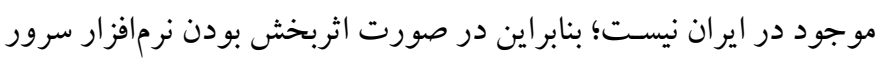

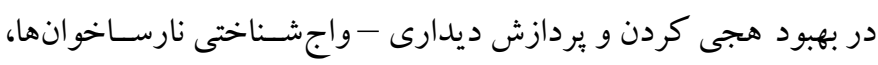

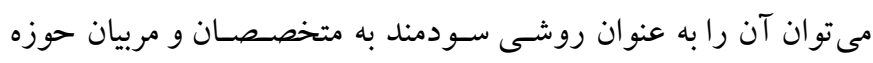
اختلالهاى ياد گيرى خاص بيشنهاد كرد.

روش

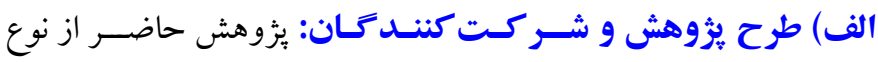

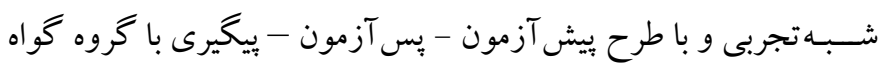

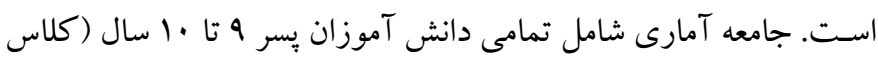

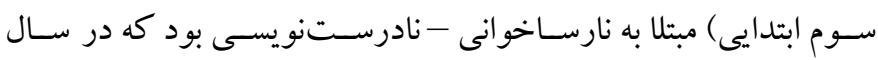
تحصيلى

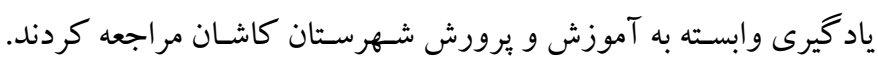

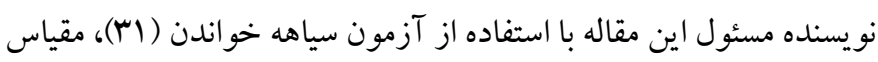

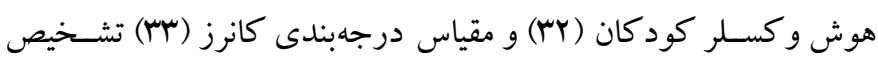

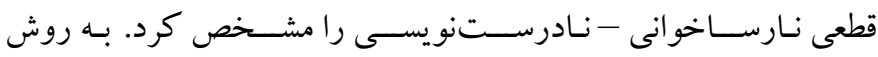

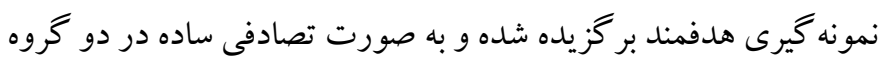

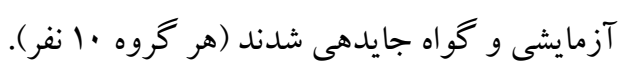

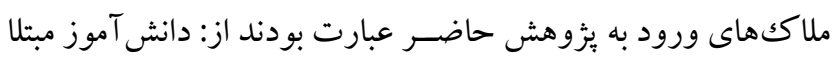

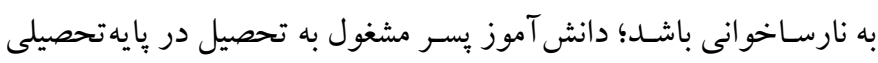

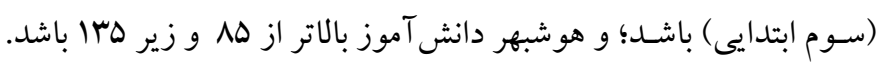

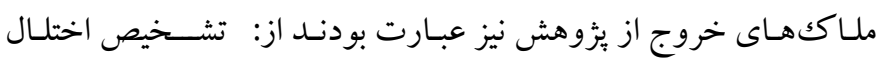

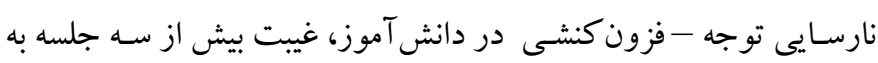

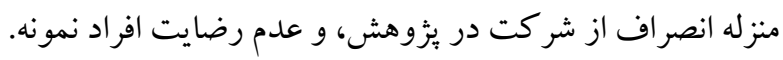

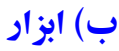
ا. آزمون سياهه خواندن ه: اين آزمون تشـخيص سريع اختلال خواندن را

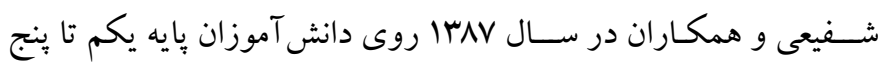

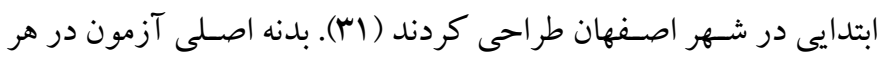

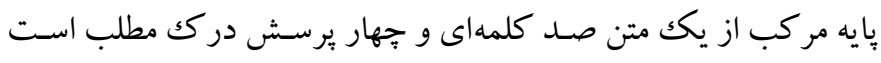

4. The Swiss Federal Institute of Technology in Zurich and the University of Zurich

5. Inventory Reading Test (IRT)
طر احى شـــــ و تلـاش براى ايجـاد بيونــد ميـان اين مدل و مهارتهاى در

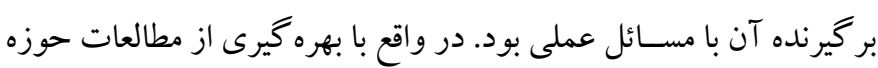

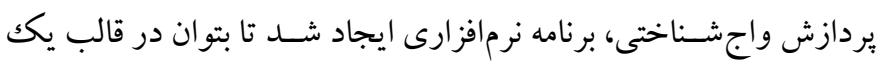

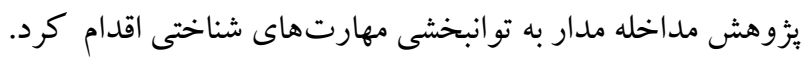

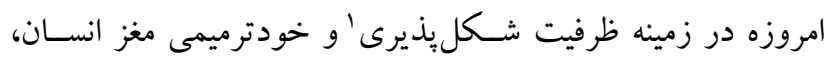

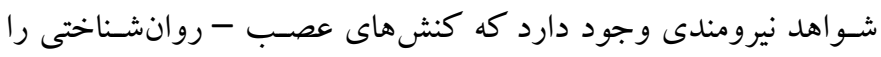

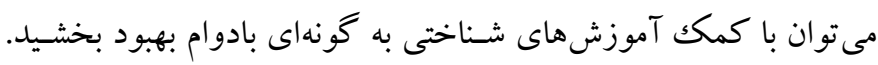

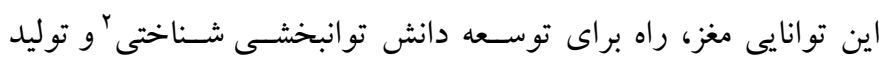

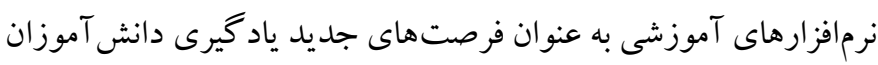

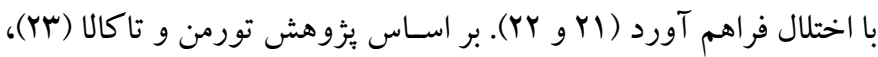

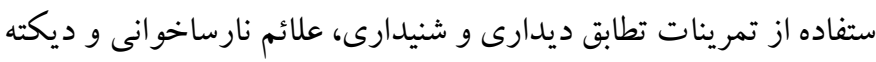

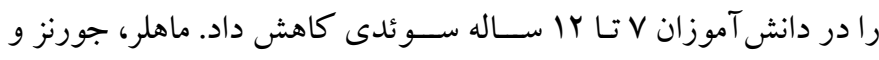

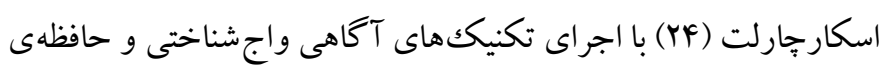

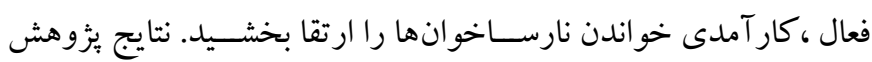

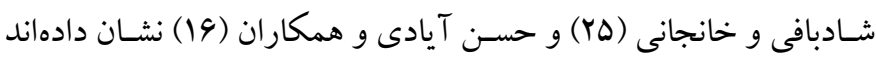

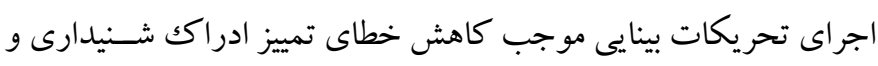

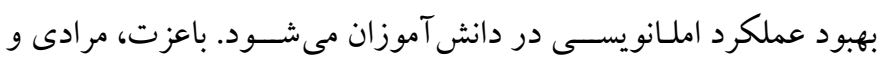

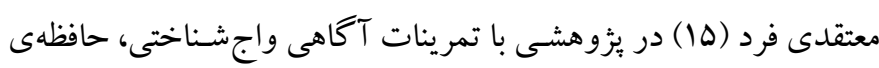

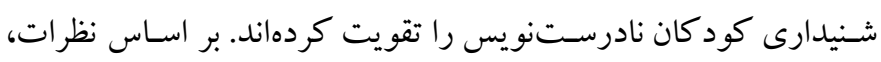

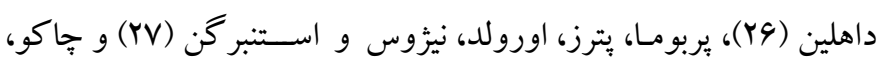

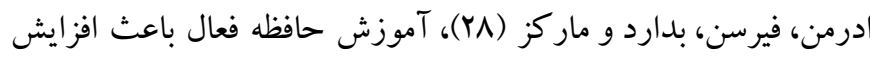
ظرفيت حافظه از طريق هدف قرار دادن ذخيرهسـازى و دســكارى لحسى اجزاى حافظه فعال كلامى و غير كلامى مى شود.

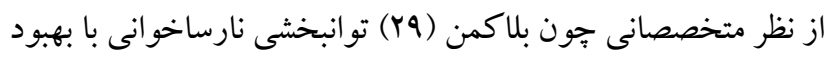

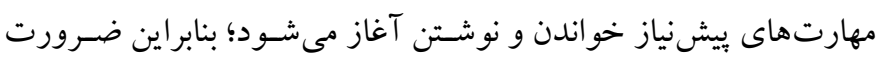

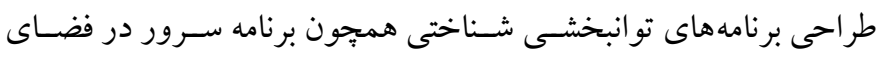

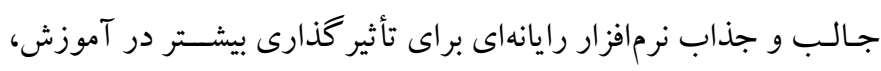

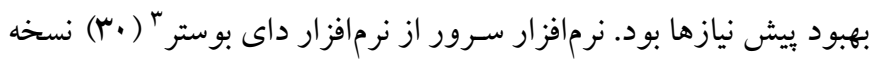

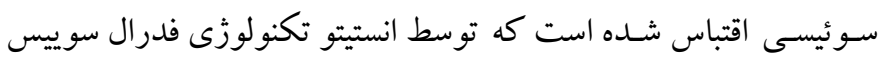
در دانشگاه تكنولوزى زوريخ "ايجاد شد و به سه زبان انگليسى، آلمانى و

1. Brain plasticity

2. Neuro-rehabilitation

3. Dybuster Orthograph 
(اصلا)، ا (تا حدودى)، ץ (زياد) و ץ (بسيار زياد) انجام مىشود و دامنه

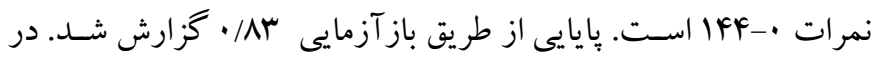

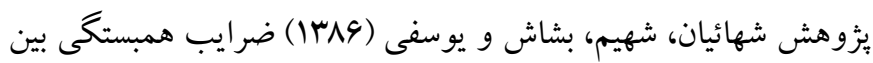

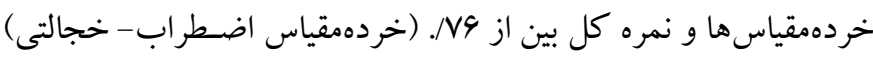

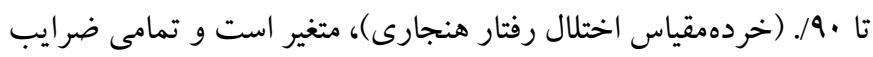

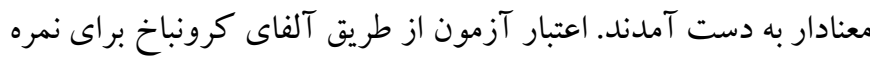

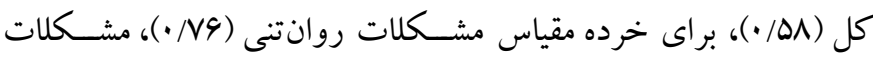

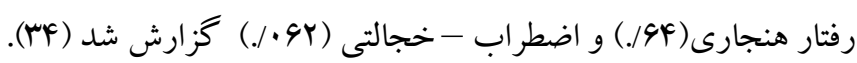

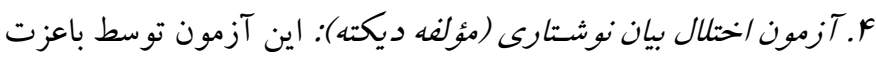

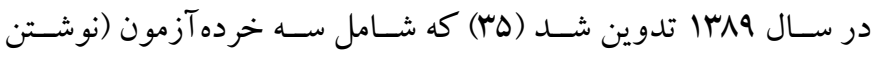
حروف، كلمه، و جمله) اسـت و از روايى و اعتبار مناسـبى در ارزيابى درسـت خطاهاى املايى دانش آموزان در بِيه ســوم ابتدايى برخوردار

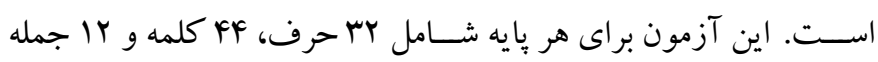

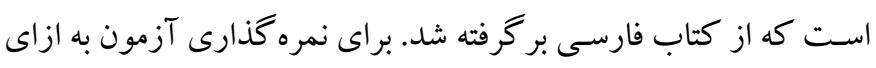

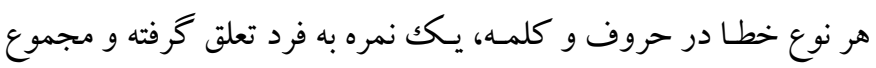

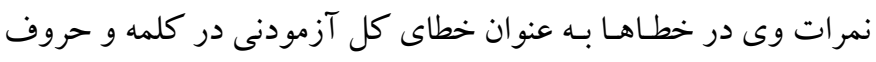

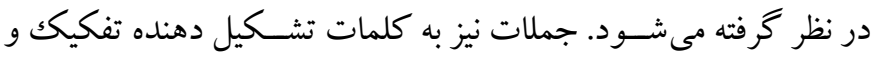

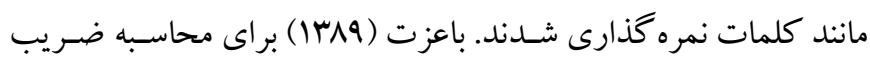

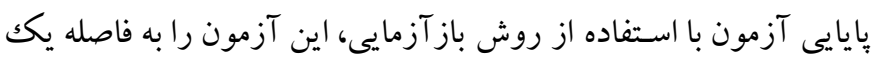

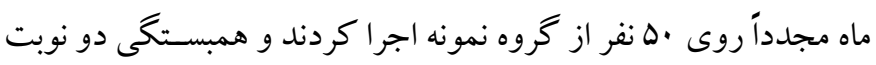

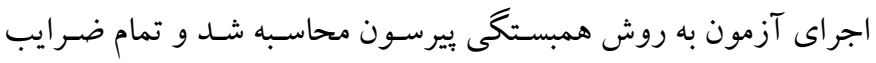

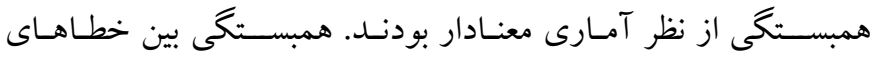

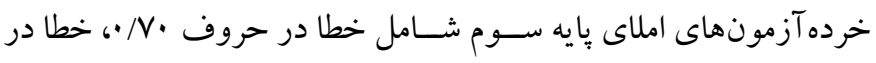

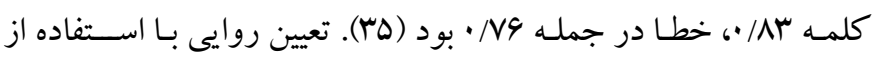

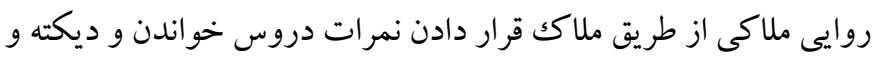

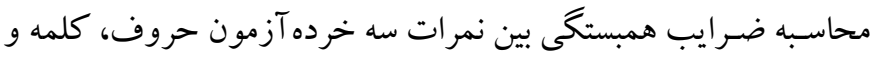

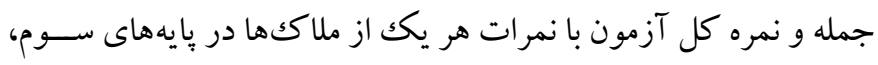

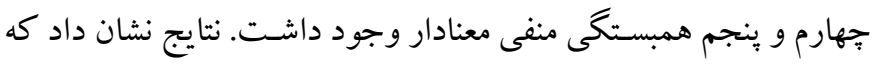

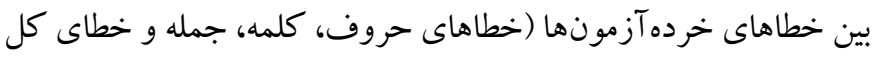

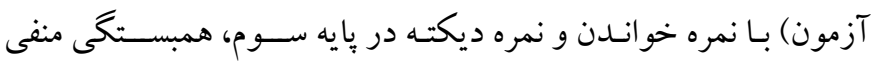

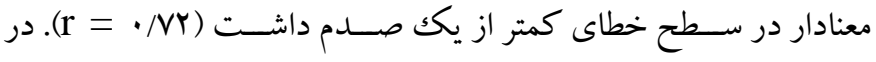

2. Conner's' rating Scale
كه توسط كارشـناس ارشــــ و كارشـناسان آسيبشناسى كفتار و زبان به دقت كنترل شـده اسـت. اين آزمون بر روى . . . دانش آموز دختر و يسر

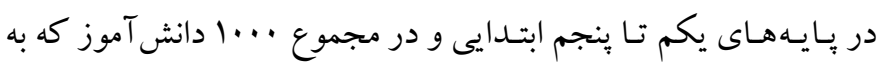

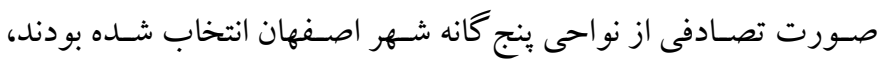

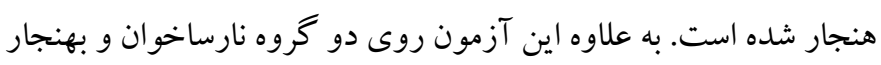

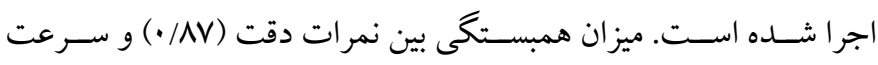

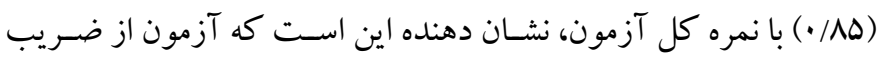
روايى مطلوبى برخوردار اسـتـ. اعتبـار آزمون بـا معبـار آلفاى كرونباخ

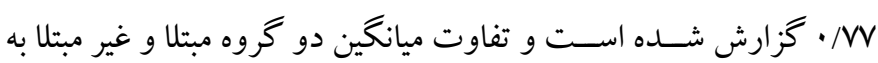
اختلال خو اندن معنادار بود.

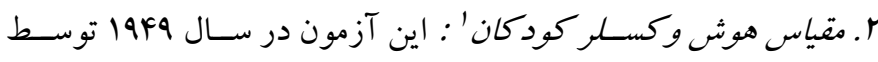

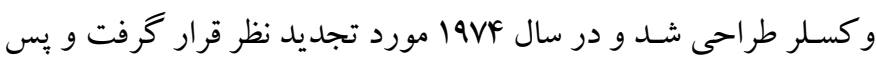
از هنجاريابى تحت عنوان آزمون هوشى تجديد نظر شده و وكسلر كود كان

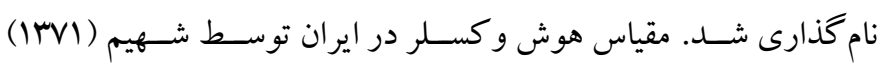

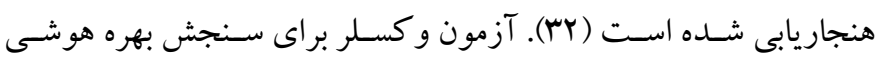
كود كان 9 تا 19 سـاله به كار مىرود. آزمون و كســلر داراى دو مقياس هوش كلـامى (شــامـل 9 خردها آزمون) و هوش غير كلـامى (شــامـل 9

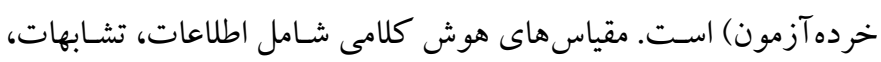

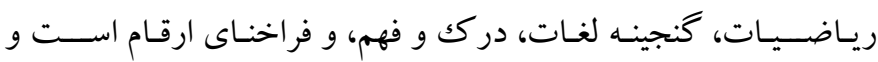

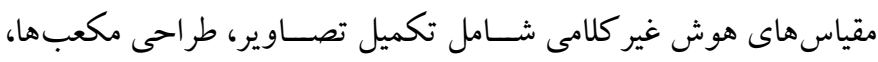

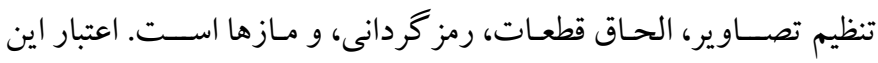

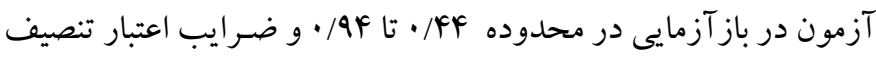

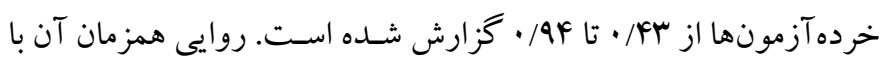

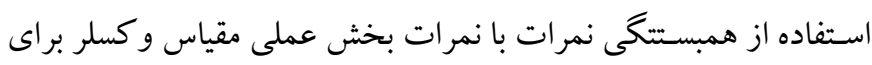

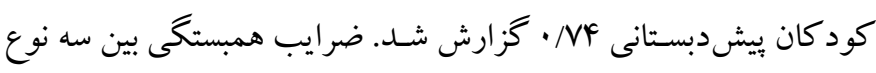

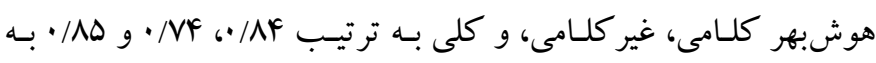

دست آمده است (اس).

r. مقياس درجهبندى كانزز": اين ابزار توسط بروك و كلينتون در سـال

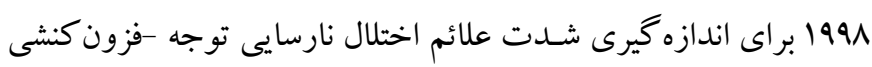

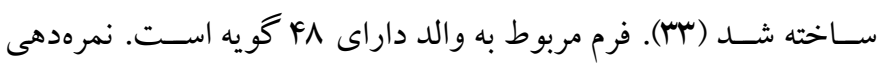

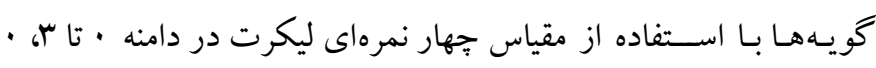


معناى ابزار روشـن شـود. در يزوهش حاضـر به شواهل ئزوهشى و ييشينه

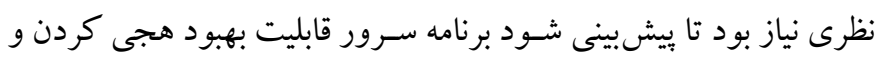

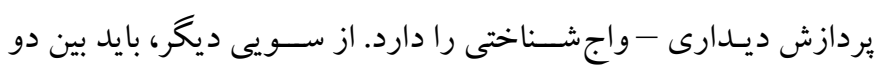

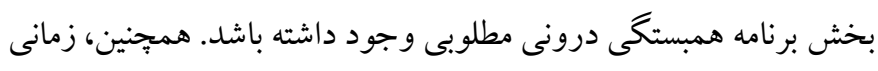

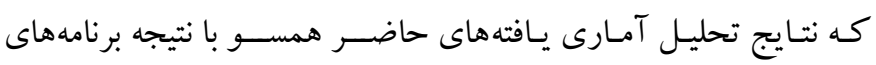

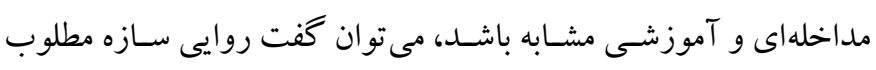
نرمافزار حاصـل شــده اسـت و جهت روايى افتراقى از نمونههاى بدون

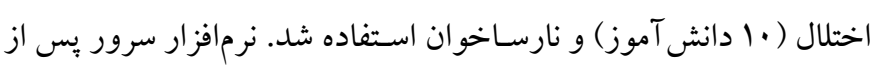

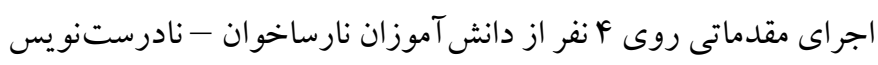

$$
\text { آماد گى اجرا بر روى گروه آزمايش را كسب كرد. }
$$

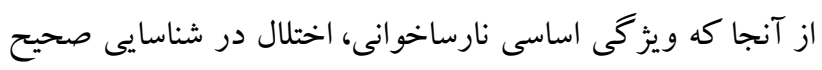

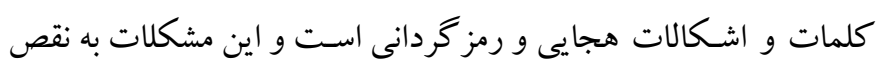

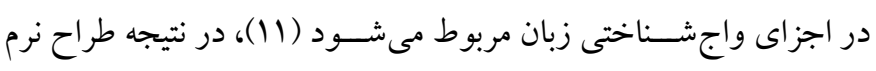

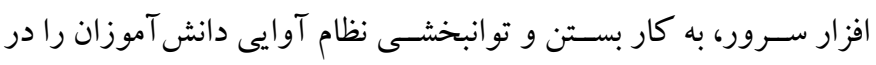

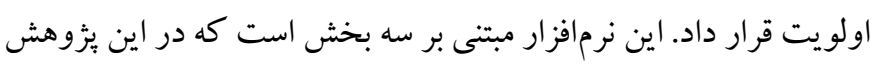

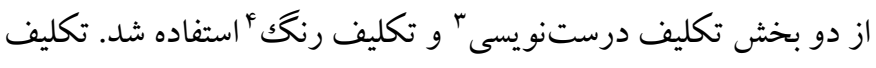

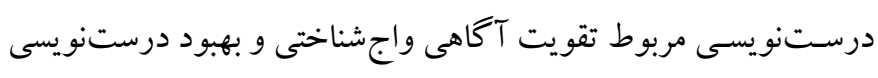

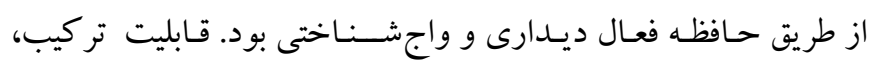

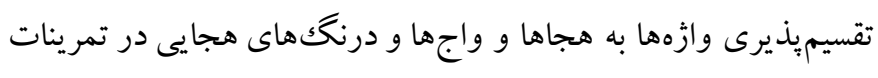

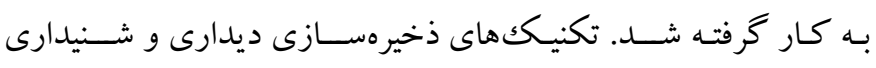

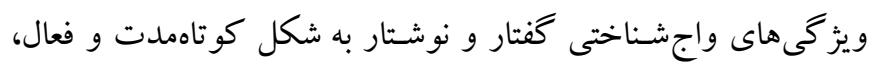

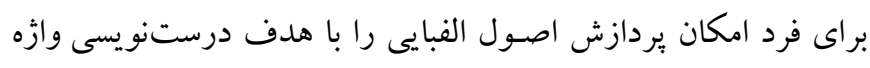
فراهم آورده است. شكل ارتباطات بينايى-واجى بين كلمات نوشتارى

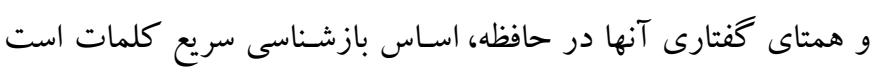

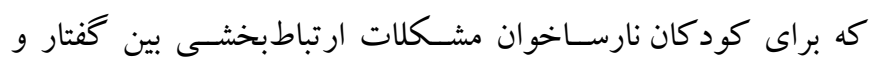

نوشتار در محور توجه تمرينات تكليف درستنويسى بود (و (Y-r9).

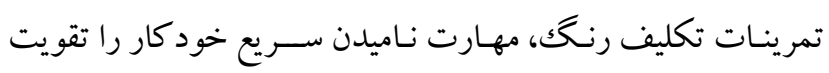
مى كند. به كفته متخصسصـان توانايى ناميدن سـريع محر ككهاى بينايى

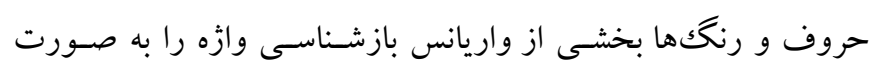

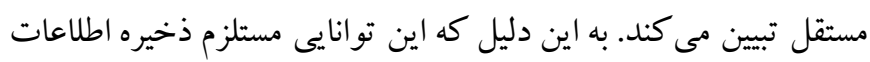

\section{Orthogragh task}

4. Color task
يُزوهش حاضــر از اين آزمون براى متغير هجى كردن يا ديكته اسـتفاده شد.

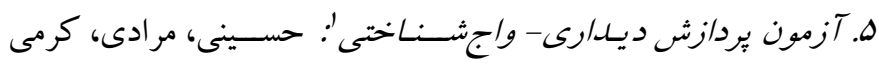

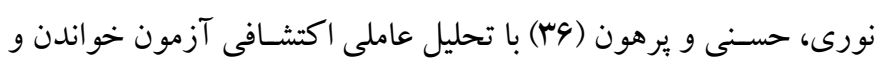

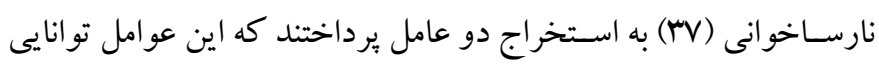

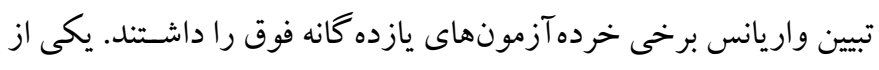

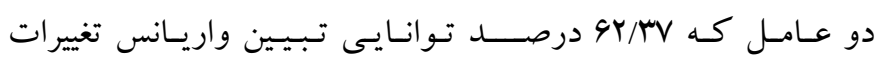

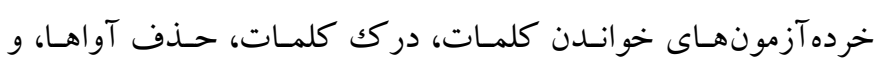

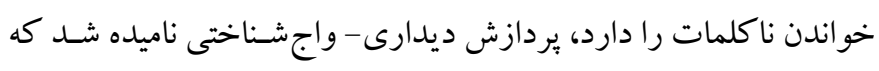

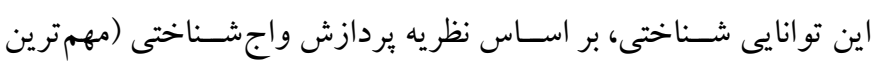

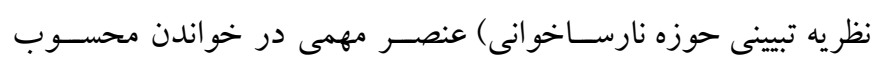

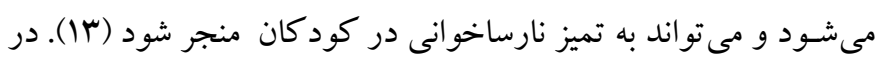

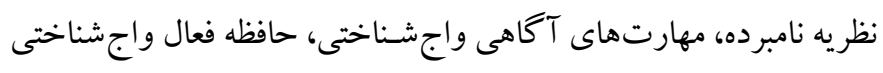

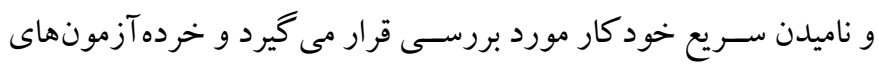

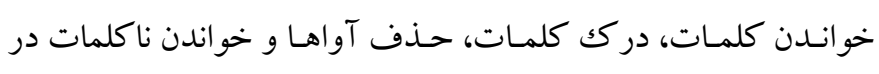

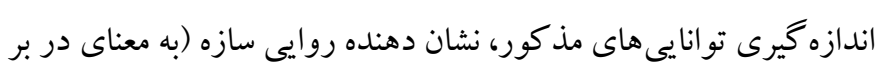

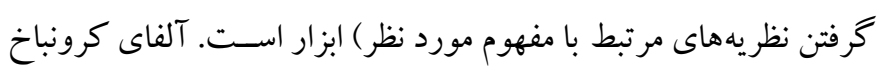

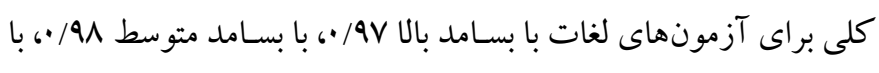

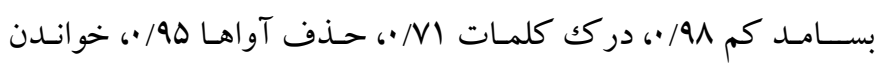

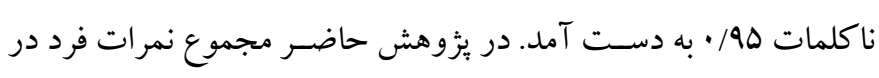

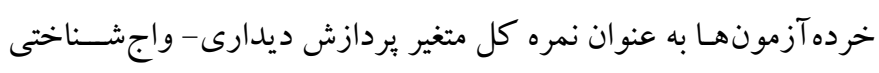

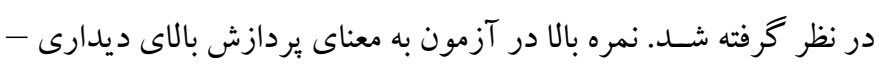

$$
\text { واجناختى است و برعكس. }
$$

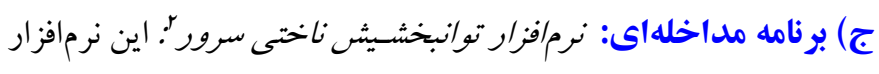
توسط معتقدى فرد به سـريرستى باعزت و نجاتى و همكارى مركز علوم

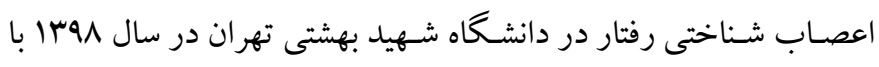

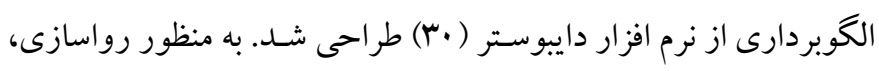

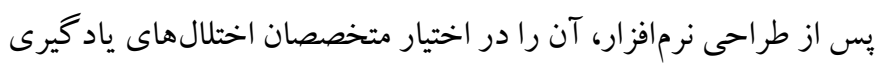

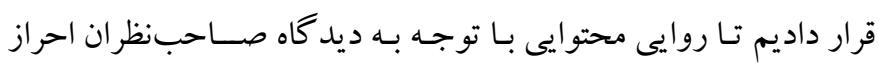

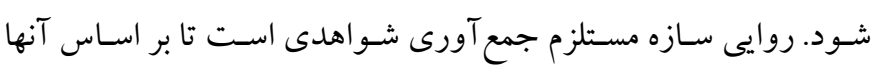


در جدول ا محتوا و اهداف مازولهاى نرمافزار توانبخشى شناختى سرور در جلسات آموزش ارائه شده است.
در حافظه فعال اسـت و خواندن را از طريق آكاهى واجشـناختى و بردازش اورتو گر افى بيشبينى مى كند (Y) (Y)

جدول ا: محتوا و اهداف مازولهاى نرمافزار توانبخشى شناختى سرور در جلسههاى آموزش

\begin{tabular}{|c|c|c|}
\hline مدت زمان & مازولها & نومافزار سرور \\
\hline \multirow{7}{*}{ 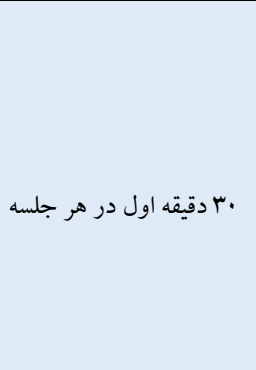 } & كلماتى با بسامد زياد، متوسط و كم & \multirow{8}{*}{ تكليف درستنويسى } \\
\hline & اضافه، حذف و جابجايى حروف در كلمه & \\
\hline & كلمات مركب & \\
\hline & كلمات استثنايى & \\
\hline & 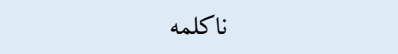 & \\
\hline & كلمات يِشوندى & \\
\hline & 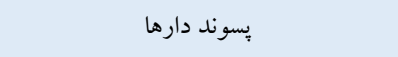 & \\
\hline \multirow{9}{*}{ 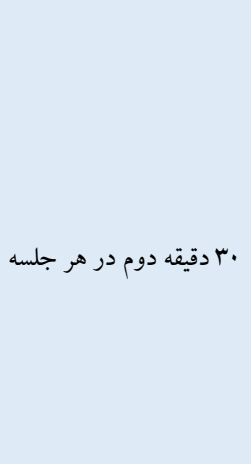 } & كلمات با حروفى داراى صداى مشابه & \\
\hline & كلماتى با بسامد زياد، متوسط و كم & \multirow{8}{*}{ تكليف رنك } \\
\hline & اضافه، حذف و جابجايى حروف در كلمه & \\
\hline & كلمات مركب & \\
\hline & كلمات استنايى & \\
\hline & ناكلمه & \\
\hline & كلمات يِيشوندى & \\
\hline & ي بسوند دارها & \\
\hline & كلمات با حروفى داراى صداى مشابه & \\
\hline
\end{tabular}

اختلال هاى ياد گيرى وابسته به آموزش و برورش شهرستان كاشان بر گزار

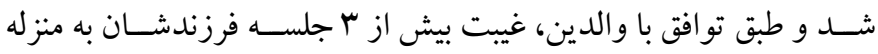
انصـراف از شركت تلقى مىشد. پِ از هر جلسه مداخله، بازخوردهاى

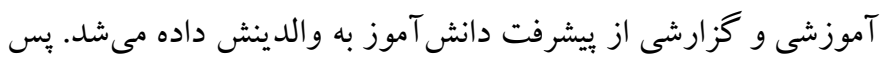

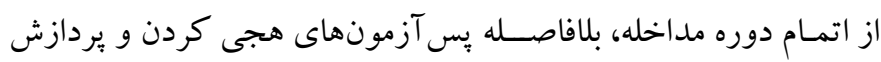

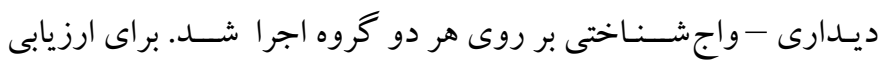

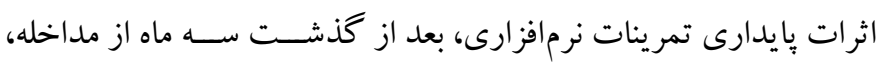

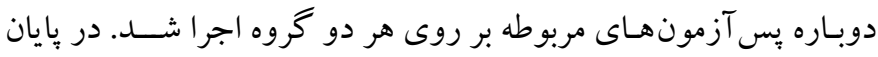

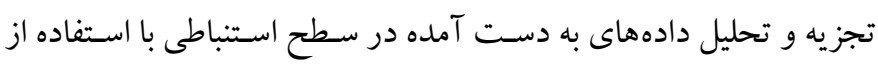
آزمون تحليل واريانس جندمتغيرى با اندازههاى مكرر استفاده شد.

\section{يافته ها}

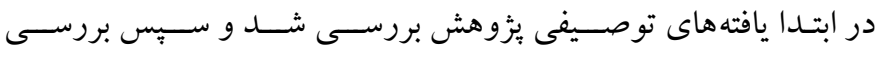

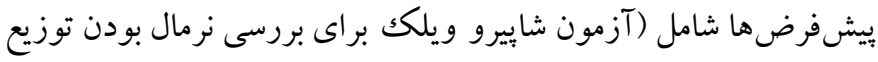

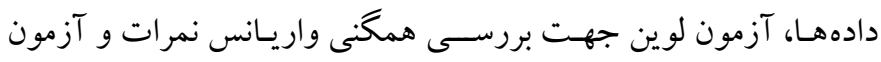

د) روش اجرا: ابتدا با گرفتن مجوزهاى للزم از گروه روانشـناسـى

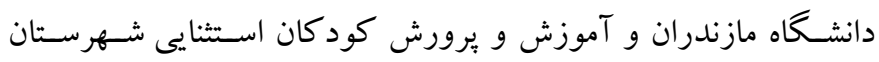

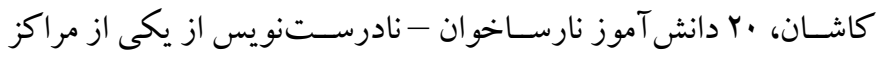

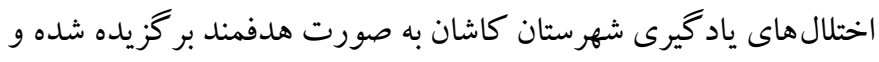

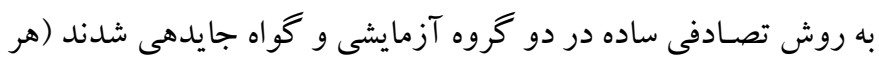

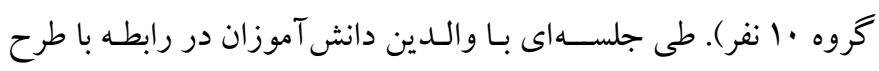

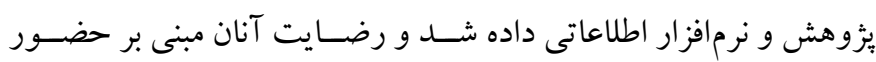
فرزندشان در اين طرح به صورت كتبى اخذ شد.

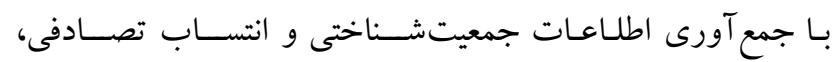

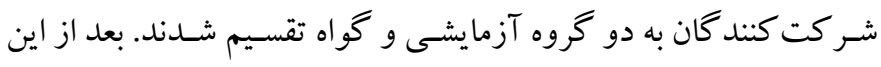

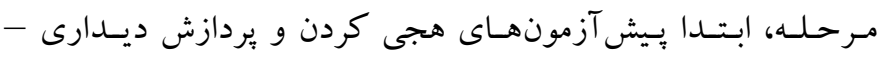

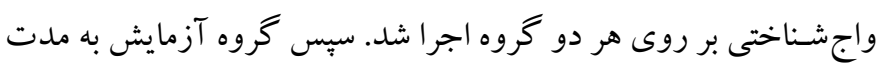

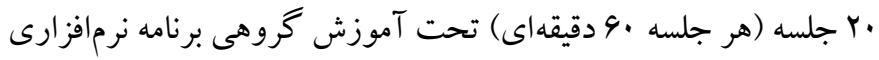
تو انبخشى سـرور توسط نويسـنده مسئول اين مقاله قرار گرفتند. جلسات

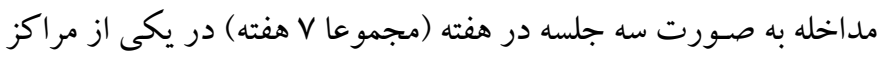


نتيجه طرح مورد استفاده طرح درون -بين آزمودنى ' اسـت. در جدول Y ميانكين، انحر اف استاندارد و همجينين نتايج آزمون شـاييرو ويلك بر اي بررسـى نرمال بودن توزيع دادهها در گروهها در ســه بازه زمانى گزارش

شده است.
مـاجلى جهـت بررسـى يكنواختى كوواريـانسهـا) و در نهايـت تحليل

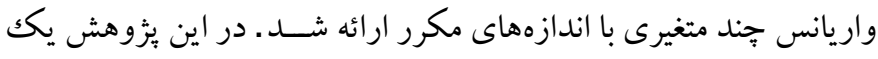
عـامـل درون آزمودنى وجود داشــت كـه زمـان انـدازه كيرى متغيرهـاى يُزوهش در سـسه مرحله بيش آزمون، بس آزمون، و آزمون بيخيرى بود و يكك عامل بين آزمودنى وجود داشـت كه آن عضــويت كروهى بود. در

جدول r: شاخص هاى توصيفى متغيرهاى يزوهش براى كروه آزمايش و كواه در سه مرحله ييش آزمون، يس آزمون، و ييكيرى

\begin{tabular}{|c|c|c|c|c|c|c|}
\hline معنادارى & آزمون شاييرو ويكك & انحراف استاندارد & ميانكين & & & متغير \\
\hline$\cdot / 91$ & $\cdot / 91$ & $9 / \Delta r$ & $\Delta F / \Delta$. & آزمايش & \multirow{2}{*}{ ييش آزمون } & \multirow{12}{*}{ هجى كردن } \\
\hline$\cdot / 49$ &.$/ 9$. & $r / 94$ & $\Delta V / 9$. & كواه & & \\
\hline • & $\cdot / M$ & $\mid q / \cdot \Delta$ & $r \Delta / \Delta$. & آزمايش & \multirow[b]{2}{*}{ پِ آزمون } & \\
\hline$\cdot / \cdot \wedge$ & •/^९ & $f / \cdot 1$ & $\Delta N / 1$. & كو اه & & \\
\hline .1 .9 & •/19 & $Q / \Gamma \Delta$ & $19 / 1$. & آزمايش & \multirow{2}{*}{ يِيَيرى } & \\
\hline.$/ 9 F$ & $\cdot / 9 V$ & 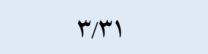 & $\Delta 1 / r$. & كواه & & \\
\hline$\cdot / r \Delta$ &.$/ 9$ & r. & $r \Delta Q / 1$. & آزمايش & \multirow{2}{*}{ يِش آزمون } & \\
\hline$\cdot 119$ & •/19 & $r \mid / 19$ & $r \mid r / r$. & كواه & & \\
\hline$\cdot / 99$ &.$/ 90$ & $\mathrm{rV} / \mathrm{Ar}$ & $\pi r r / r$. & آزمايش & \multirow{2}{*}{ 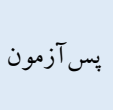 } & \\
\hline$\cdot / A F$ & $\cdot / 99$ & $\kappa r / 0$. & $r \notin q / r$. & كواه & & \\
\hline$\cdot / v$ & $\cdot / 90$ & $r V / r$. & $M r q / 9$. & آزمايش & \multirow{2}{*}{ ييكيرى } & \\
\hline 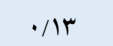 & $\cdot / M$ & $99 / \Gamma \Delta$ & $r F Q / F$. & كواه & & \\
\hline
\end{tabular}

اســت بنـابر اين بـا اطمينـان بـالـايى مى توان نمرات هجى كردن را نرمال

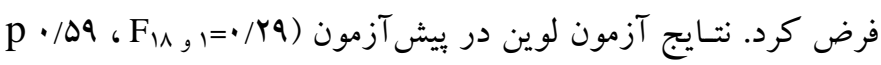

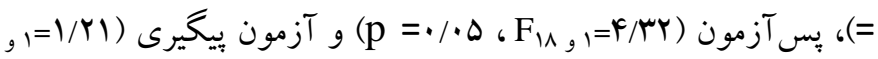

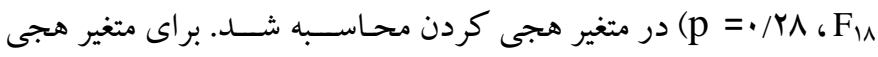
كردن از تصسحيح كرينهاوس كيســـ براى بررسـى مفروضسه كرويت بارتلت مبنى بر برقرارى مفروضـه همكنى واريانس خطا اسـتفاده شـــ (p =/VF) يردازش ديدارى - واجشـناختى طبق آزمون ام باكس (ه • = = p ) مورد بررسى قرار گرفت و برقرار بودن همه مفروضهها تأييد شد.
نتايج جدول r مشـخص كرد ميانگين و انحر اف اسـتاندارد گروهها در مرحله بيش آزمون، تقريباً به هم نزديكك بوده؛ ولى در مرحله يُس آزمون و آزمون بيخيرى، اين كميـتها در كروههاى آزمايش با واريانس بيشترى نسبت به گروه گواه مواجه شدهاند. يكى از اهداف اين يثوهش بررسسى تأثير برنامه توانبخشسى شـناختى

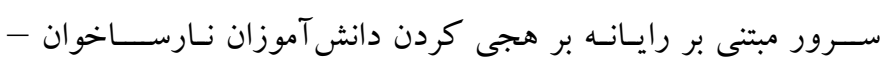
نادرستنويس است كه جهت انجام آزمون تحليل واريانس جندمتغيرى با اندازههاى مكرر، ابتدا مفروضـهههاى آن مورد بررسـى قرار گرفت. با توجه به جدول ب سـطح معنادارى در آزمون شاييرو ويلك بالاتر از هـ/

جدول rّ: نتايج تحليل واريانس جند متغيرى با اندازههاى مكرر براى اثرات بين كروهى

\begin{tabular}{|c|c|c|c|c|c|c|c|}
\hline مجذور اتا & سطح معنادارى & درجه آزادى خطا & درجه آزادى فرض & $\mathbf{F}$ & ارزش & آزمون & منبع تغيير \\
\hline$\cdot / \wedge \mathrm{V}$ & $\%$ & IV & $r$ & $\Delta V / T Y$ & $\cdot / \mathrm{AV}$ & اثر ييلايى & هجى كردن \\
\hline
\end{tabular}




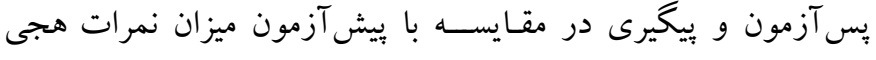

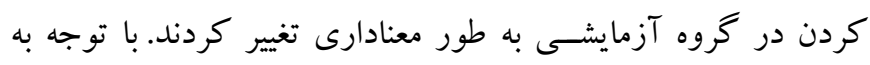

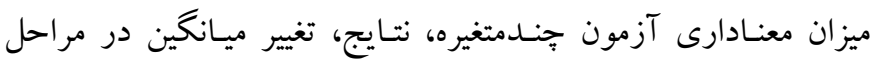

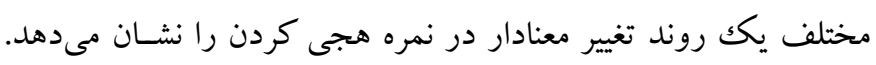

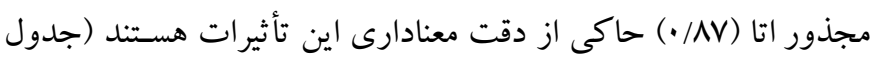

(r)
نتايج آزمون تحليل واريانس جندمتغيره با اندازهگيرىهاى مكرر

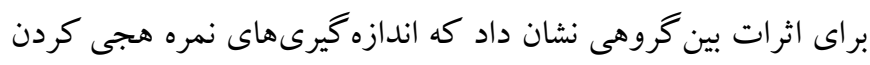

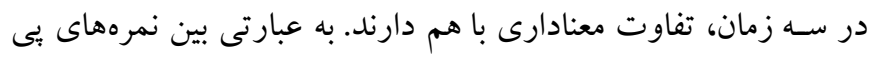

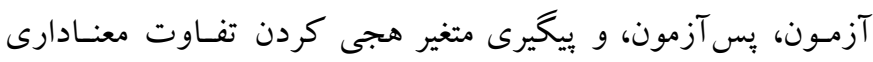

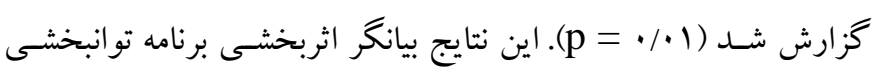

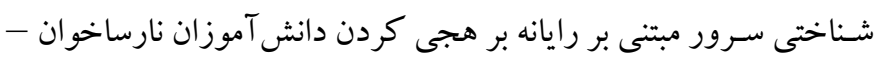

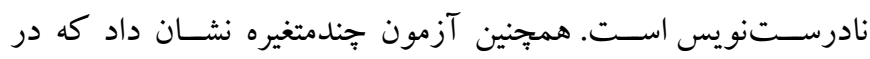

جدول ع: نتايج تحليل واريانس بين آزمودنى و درون آزمودنى

\begin{tabular}{|c|c|c|c|c|c|c|}
\hline اندازه اثر & معنادارى & $\mathbf{F}$ & ميانكين مجموع مجذورات & درجه آزادى & مجموع مجذورات & منبع تغيير \\
\hline \multicolumn{7}{|c|}{ درون آزمودنىها } \\
\hline$\cdot / \mathrm{WV}$ & $\%$ & $9 Y / \cdot 1$ & FAGY/.Y & 1 & FAST/.r & مراحل يزوهش \\
\hline \multirow[t]{2}{*}{.$/ 94$} & $\cdot / \cdot$ & 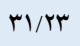 & YFFQ/YY & & YFFQ/YY & تعامل بين مراحل بثزوهش و عضويت گروهى \\
\hline & & & $V N / F$. & 11 & $|F| \mid / Y \Delta$ & خطا \\
\hline \multicolumn{7}{|c|}{ بين آزمودنىها } \\
\hline \multirow[t]{2}{*}{$\cdot / \mathrm{WV}$} & $\cdot / \cdot$ & $9 Y / 9 V$ & $1 . r V \Delta / T \Delta$ & 1 & 1. TVQ/TD & عضويت گروهى \\
\hline & & & $194 / V D$ & 11 & rQQQ/GT & خطا \\
\hline
\end{tabular}

انجام تحليل واريانس جند متغيرى با اندازههاى مكرر، ابتدا مفروضـههاى آن آزمون شـد. با توجه به جدول Y سـطح معنادارى در آزمون شـاييرو ويلكك بـالـاتر از ه • • اســت، بنـابر اين بـا اطمينان بالايى مى توان نمرات يردازش ديدارى - واجشــناختى رانرمال فرض كرد. نتايج آزمون لوين

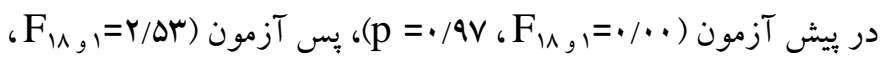
r p ديدارى - واجهـناختى محاسـبه شـد. يافته ها نشـان داد كه بين واريانس متغيرها دو گروه در سـه بازه زمانى تفاوت معنادارى وجود ندارد و فرض

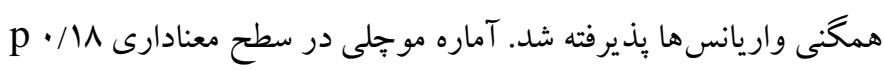
= مفروضسه كرويت بارتلت مبنى بر برقرارى مفروضسه همخنى واريانس خطا در بردازش ديدارى - واجشناختى را تأييد كرد.
بر اســاس يافته هاى به دسـت آمده در جدول Fا، تفاوت بين نمرات هجى كردن در سـه مرحله از يثزوهش معنادار اسـت ( ( • > p). همجينين ميانگين نمرات اين متغير در دو گروه آزمـايش و گو اه تفاوت معنادارى

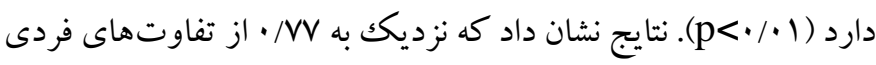
در اين متغير به تفاوت بين دو گروه مربوط اسـت. علاوه بر اين تعامل بين

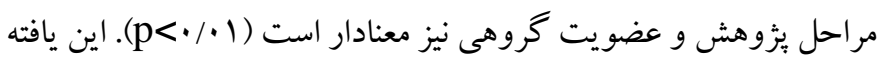
بـه معنـاى آن اســت كـه بين كروه آزمـايش و گو اه تغيير معنـادارى در ميـانگين نمره هجى كردن نـارسـاخوانها از بيش آزمون به يس آزمون و

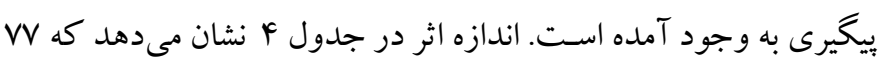
درصـــد از تغييرات در هجى كردن كودكـان در طول زمـان مربوط بـه توانبخشى شناختى نرمافزار سرور است. همجِين در اين مطالعـه تـأثير برنـامـه ســـرور بر بردازش ديدارى واجشناختى دانش آموزان نارساخوان - نادرستنويس بررسى شد. جهت

جدول 0: نتايج تحليل واريانس جندمتغيرى با اندازههاى مكرر براى اثرات بين كىوهى

\begin{tabular}{|c|c|c|c|c|c|c|c|}
\hline مجذور اتاو & سطح معنادارى & درجه آزادى خطا & درجه آزادى فرض & $\mathbf{F}$ & ارزش & آزمون & منبع تغيير \\
\hline$\cdot / \mathrm{AV}$ & $\cdot 1 \cdots$ & IV & r & $\Delta N / Y I$ & $\cdot / A V$ & اثر ييلايى & يردازش ديدارى - واجشناختى \\
\hline
\end{tabular}


بيش آزمون، ميزان نمرات يردازش ديسـارى - واجشـــــاختى در كروه آزمايشـى به طور معنادارى تغيير كردند. با توجه به ميزان معنادارى

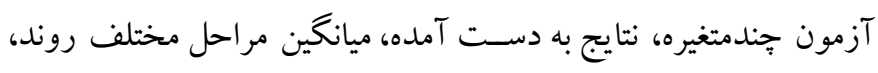
تغيير معنادارى را در نمره يردازش ديدارى - واجشـناختى را نشــان مى دهد. مجذور اتا (AVV/•) حاكى از دقت معنادارى اين تأثيرات اسـت

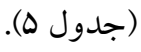

نتايج آزمون تحليل واريانس جندمتغيره با اندازهگيرىهاى مكرر بـراى اثرات بين كروهى نشـــان داد كـه نمره يردازش ديـدارى واجشـاختى در سـه زمان، تفاوت معنادارى با هم دارند. بين نمرههاى بيش آزمون، يس آزمون، و بيخيرى تفاوت معنادارى گز ارش شـد (

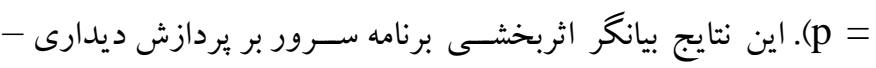
واجسـاختى دانش آموزان نارسـاخوان - نادرسـتنويس است. همجنين

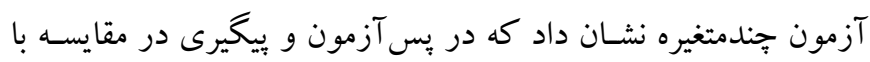

جدول ح: نتايج تحليل واريانس بين آزمودنى و درون آزمودنى

\begin{tabular}{|c|c|c|c|c|c|c|}
\hline اندازه اثر & معنىدارى & $\mathbf{F}$ & ميانكين مجموع مجذورات & درجه آزادى & مجموع مجذورات & منبع تغيير \\
\hline \multicolumn{7}{|c|}{ درون آزمودنىها } \\
\hline$\cdot / V^{F}$ & $\cdot / \cdot$ & $\Delta r / T r$ & VVIVG/YY & 1 & WVIVG/YY & مراحل يزوهش \\
\hline \multirow[t]{2}{*}{$\cdot / \Delta r$} & $\cdot / \cdot$ & rI & $r \cdot 999 / Y Y$ & 1 & $r .999 / r Y$ & تعامل بين مراحل يُزوهش و عضويت گروهى \\
\hline & & & $|F V F / 9|$ & 11 & YQDFT/.D & خطا \\
\hline \multicolumn{7}{|c|}{ بين آزمودنىها } \\
\hline \multirow[t]{2}{*}{$\cdot|A|$} & $\cdot / \cdot$ & $V Q / r v$ & IVGYDAN/F. & 1 & IVGYOA/F. & عضويت گروهى \\
\hline & & & TYY./DI & 11 & r৭৭9৭/rq & خطا \\
\hline
\end{tabular}

نـارســاخوان - نـادرســتنويس بود. نتـايج يـافتـهــاى تحليل واريانس جندمتغيره با اندازههاى مكرر مطابق انتظار نشـان داد تمرينات تو انبخشىى

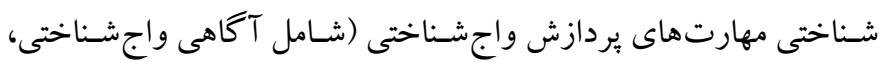
حافظه فعال واجشــناختى و ناميدن ســـريع خود كار) به كاهش خطاهاى

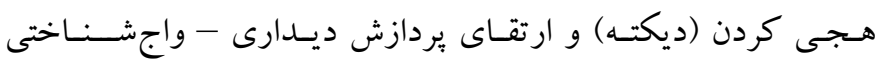
دانش آموزان منجر شد. نارسـاخوانى - نادرسـت نويسـى يكى از انواع اختلال هاى ياد كيرى خاص اسـت كه ضـعفهاى روانى كلامى، توانايى دقت در خواندن، صسحبت كردن و هجى كردن را شـامل مىشـود و مىتواند در آكاهى واجشــــاختى، رمز گشــايى ديكته، حافظه شـــنوايـى كوتاه مدت، و و

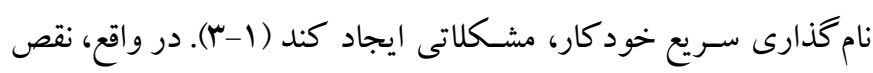
يردازش واجشــــاسـى در كـدكـذارى شــكـل واجهـاى كلمات (ماندهمقافيهسـازى، هجاها و ســلابـها)، ناميدن ســريع خود كار، حلقهاى واجشـناختى، حلقههاى اورتو گرافى، و هميجنين در ادراكك (شــامل ادراكك ديدارى، ابعاد ادراكك شـكل از زمينه، درك ثبات
بر اســاس يـافتهاى به دســت آمده در جدولو، تفاوت بين نمرات يردازش ديدارى - واجشـناختى در سـه مرحله از ئزوهش معنادار اسـت

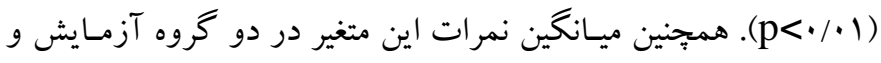

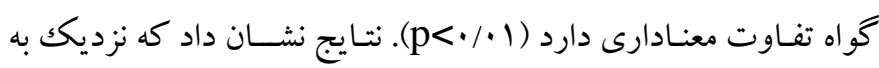
|1/ • درصـــ از تفـاوت هـاى فردى در اين متغير به تفاوت بين دو گروه مربوط اسـت. علاوه بر اين تعامل بين مراحل بثزوهش و عضويت گروهى ترو

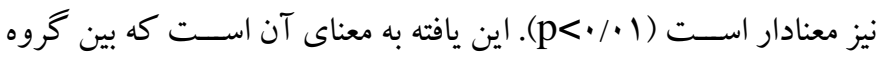
آزمـايش و كواه تغيير معنـادارى در ميـانگين نمره يردازش ديـدارى -

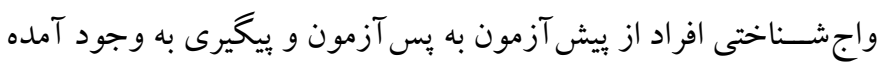
اسـت. اندازه اثر در جدول و نشـان مىدهد كه VF درصسد از تغييرات در يردازش ديسـارى - واجــــــاختى كودكـان در طى زمـان مربوط بـهـ توانبخشى شناختى نرمافزار سرور است.

\section{بحث و نتيجه تيرى}

هدف اين ئزوهش بررسى اثربخشى برنامه توانبخشى شناختى سرور مبتنى بر رايانه بر هجى كردن و يردازش ديدارى - واجشــناختى دانش آموزان 
مىشـود. تكاليف بخش درستتنويسى نرمافزار سـرور بر بهبود فرايند

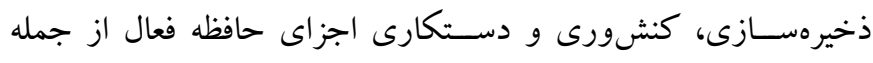

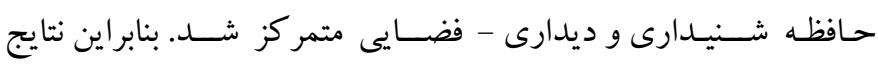

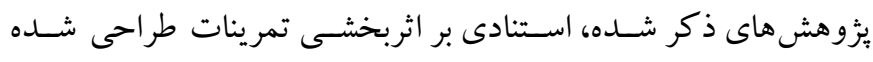

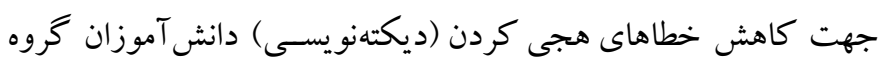
آزمايشى بود.

در مورد اثربخشى تمرينات بخش رنشك نرمافزار نيز بايد ياد آور شـد

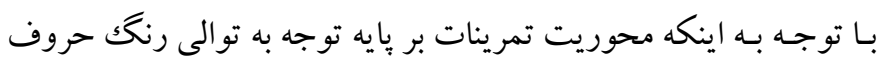

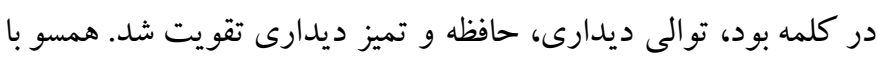

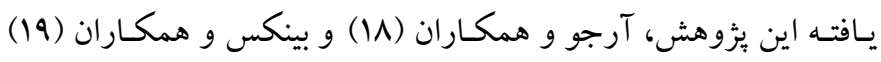
نشان دادند كه مهارت سرعت ناميدن مستلزم ذخيره اطلاعات در حافظه فعال است كه درستنويسى كلمات را امكانيذير مى دسازد. يافته ديخر در بثزوهش حاضـر مشخص كرد نمرات بردازش ديد ديدارى

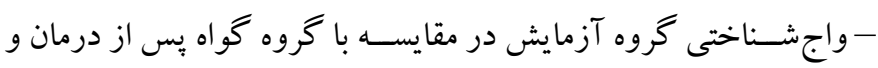

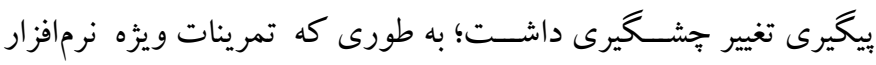

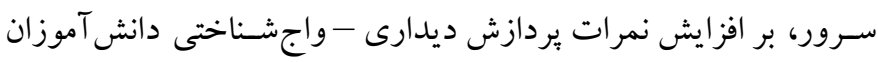
كروه آزمايش اثربخش بود. مطالعات حوزه روانشـناسى شــناختى نشان

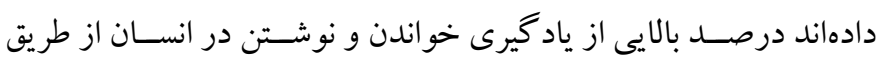
يردازش هاى ديدارى - واجشـناختى انجام مى شـود (1). نظريه يردازان

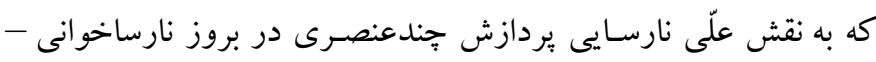

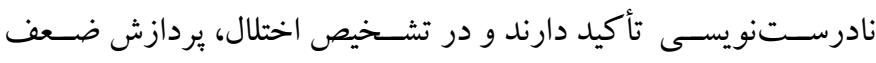
ديدارى - واجشـناختى را اسـاس قرار مىدهند (9 و • (1) معتقد هســتند

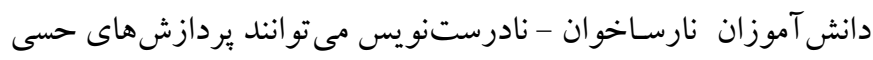
خود را با تو انبخشى تغيير دهند و در بهبود مهارتهاى تحصيلى خودة،

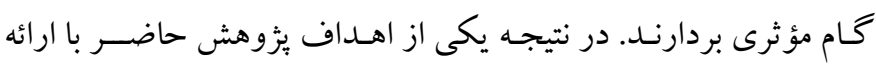

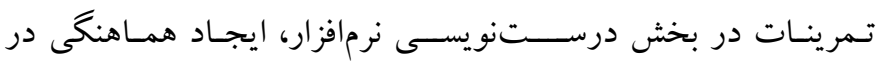

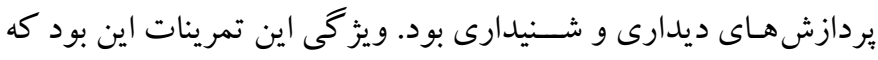

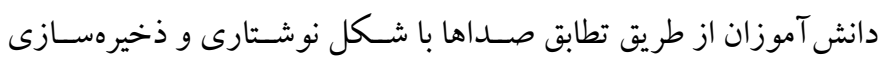
ديدارى - شنيدارى كفتار و نوشتار به شكل كو تاهمدت و فعال، برايشان

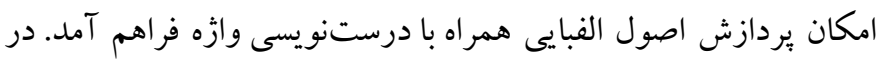
واقع، شـكل ارتباطات بينايى واجى بين كلمات نوشـتارى و همتاى

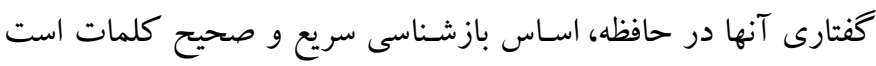

شـكل، ادراك شــنيدارى، هماهنكى ديدارى - حركتى، و ادراكى ديدارى - حركتى) از علل زيربنايى نارساخوانى - نادرستنويسى هستند

$(Y F, F)$

از ديد كاه برخى متخصـصـان از جمله وســت وود (ه) ارزيابى اين

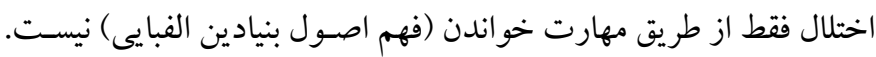

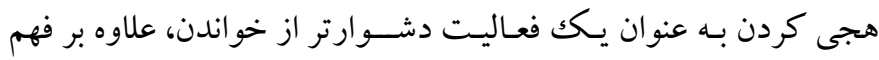
اصسول بنيادين الفبايى، نيازمند كسب مهارتهايى در زمينه روابط منظم

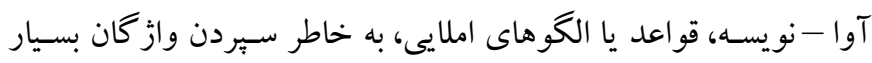

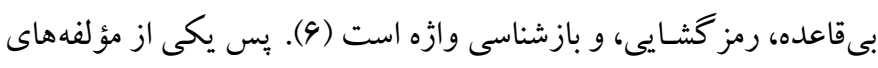

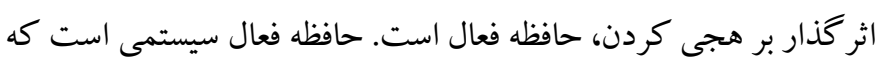

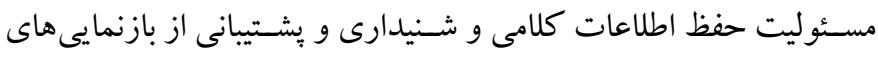

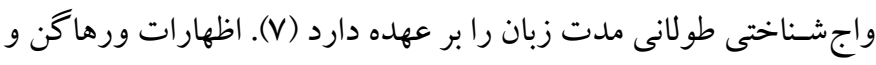

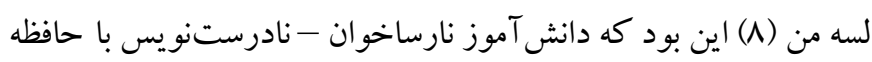

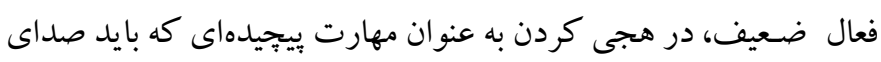

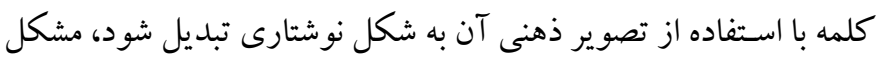

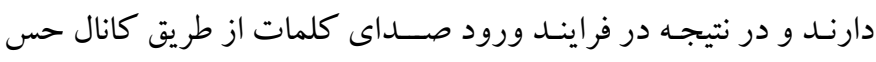

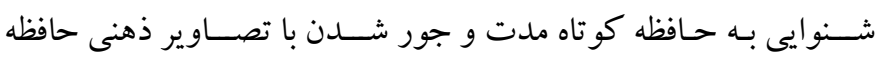

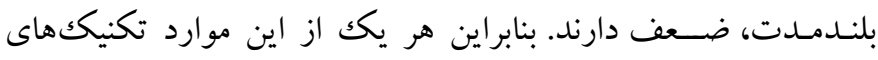
آموزشى - درمانى ويزهاى را مى طلبند. در واقع، در ياد گيرى هجى صسحيح كلمات نقش بازنمايى، ذخيره و

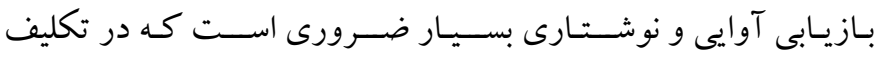

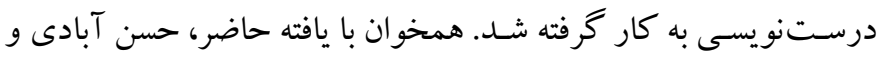

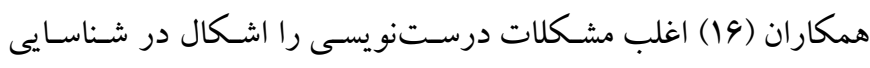
حروف الفـبـا، جـايخـاه حروف، حروف هم آوا، معنـاى كلمـات، ذخيرهسـازى و بازيابى اطلاعات ديدارى تشخيص داد و با اجراى شيوه

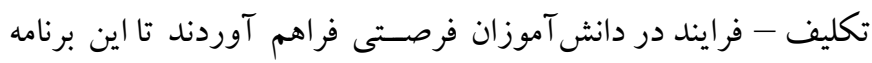

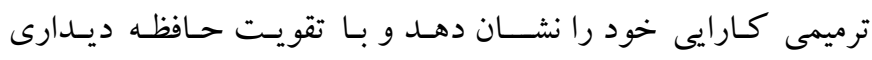

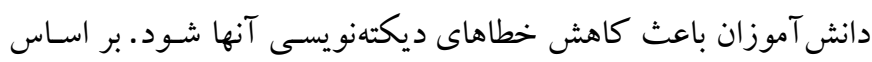

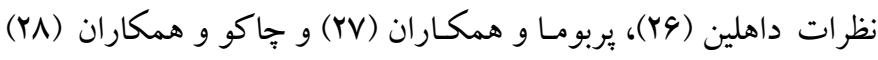
آموزش حافظه فعال از طريق هدف قرار دادن دو عامل مهم حافظه از جمله ذخيرهسازى و دستكارى اجزاى حافظه فعال كلامى (واجشناختى)

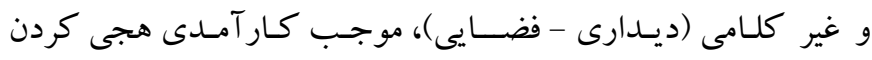


درستنويسى است بايد به تقويت و ترميم اين فرايندهاى روانشناختى

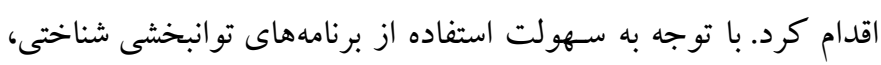

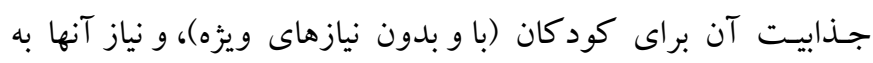

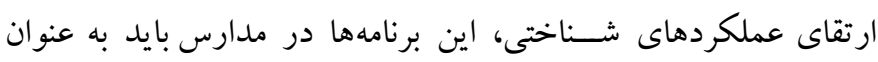

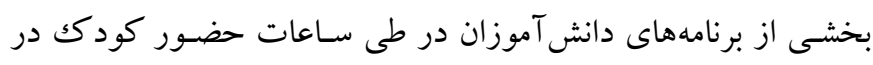
مدرسه ارائه شود.

ييشــنهاد مىشـود نتايج اين يثزوهش در مدارس و مراكز اختلالات ياد گيرى جهت كمكك به مهارت خواندن و درستنويسى دانش آموزان

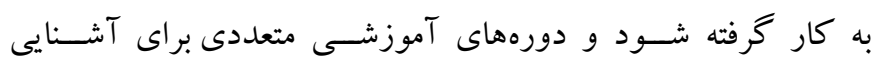

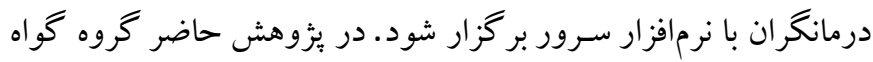

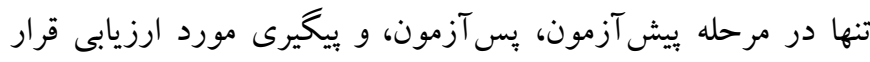

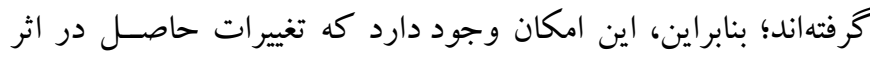

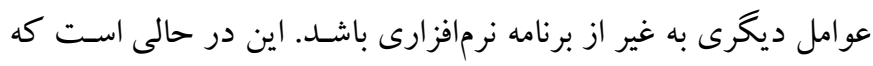

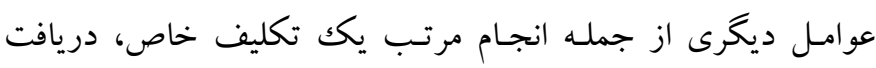
يسخوراند، به جالش كشيده شدن توسط تكليف جديد، تماس و تعامل

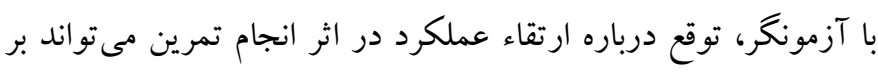

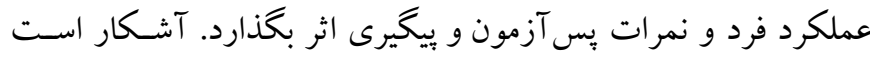

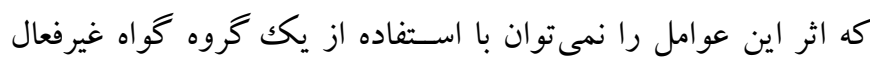

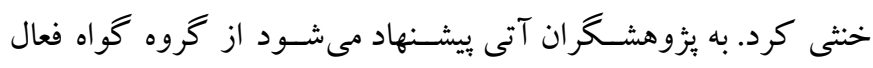

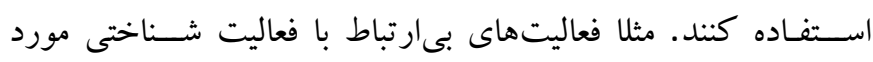

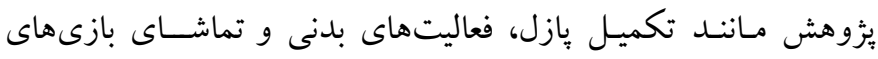
كامبيوترى مورد استفاده قرار گيرد.

\section{ملاحظات اخلاقى}

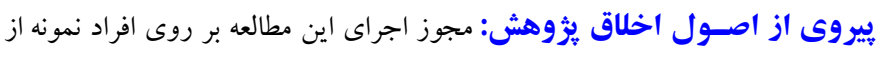

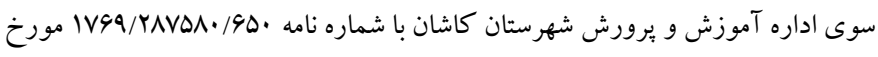

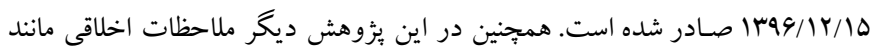

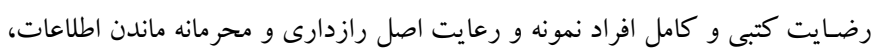

رعايت شده است. حامى مالى: اين مطالعه بدون حامى مالى و در قالب رساله دكترا انجام شده است.

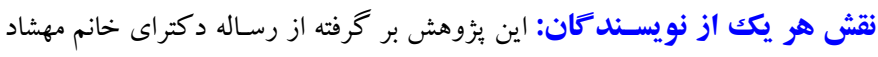

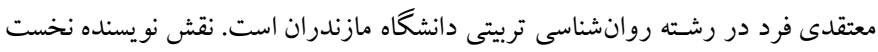

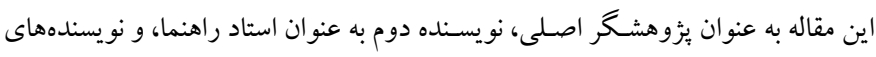

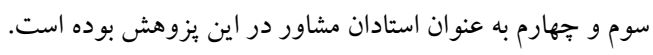

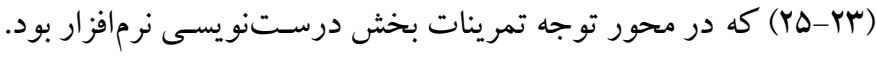

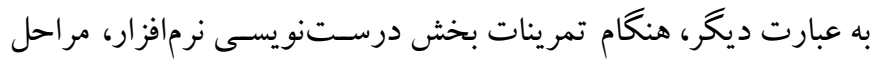

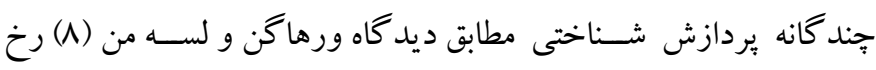

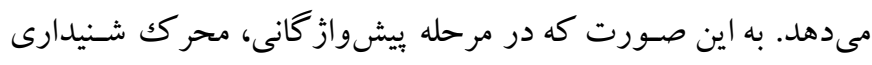

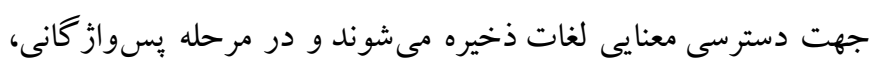
لغات مورد نظر جهت نوشـتن در صـفحه نمايش كامبيوتر، از واز كان دهان

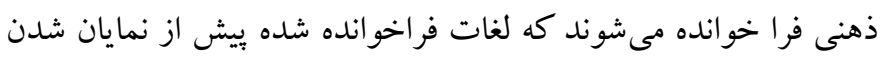

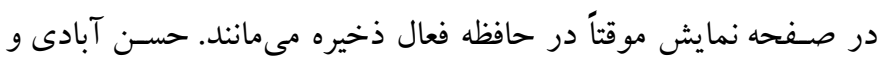

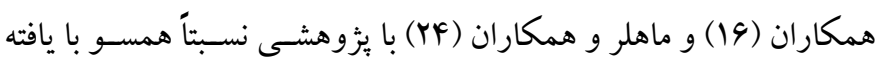

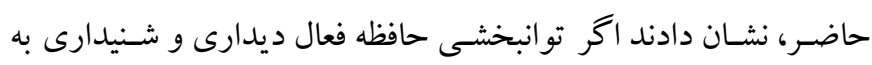
بهبود عملكرد در تكاليف هجى كردن به خصـوص حروف هم آوا ناشسى از ضـعف حافظه ديدارى منجر شـود، يردازشهاى ديدارى و واجناختى هم بهبود مى يابد.

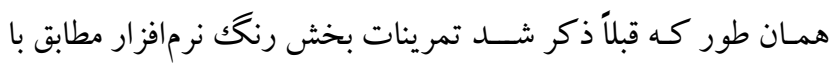

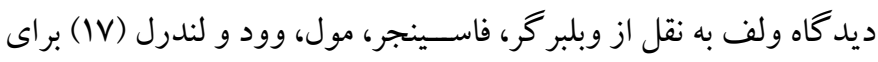

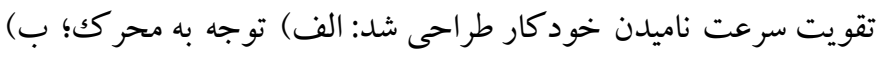

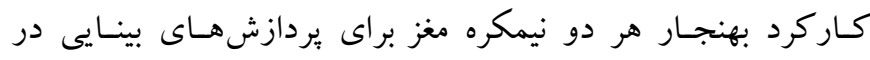

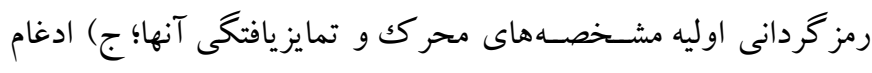

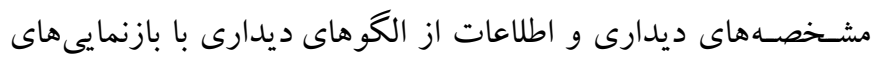

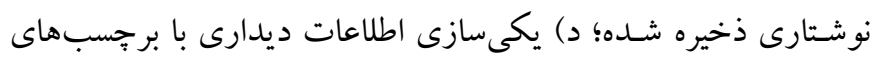
واجشـناختى ذخيره شــده؛ و ه) فعالسـازى حركتى كه منجر به توليد

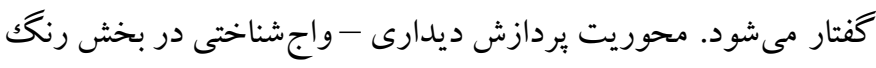

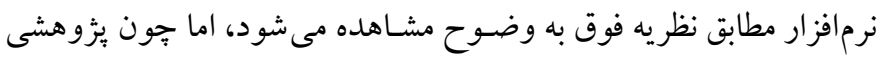

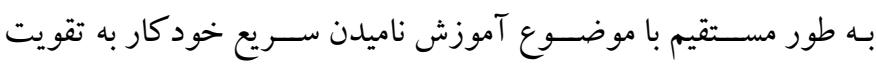

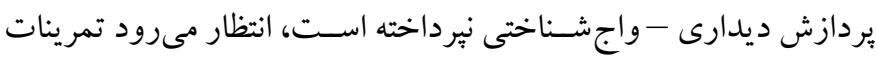
بخش رنگك نرمافزار در بهبود اين كار كرد شناختى مؤثر واقع شده باشد.

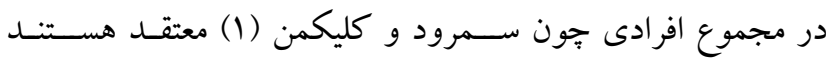
كار كردهاى شناختى بروندادهاى رفتار را تنظيم مى كنند و نقص در در آنها

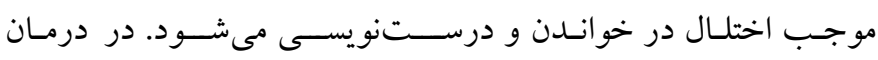

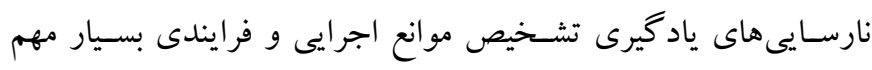

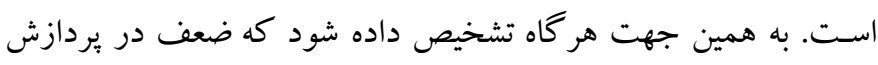

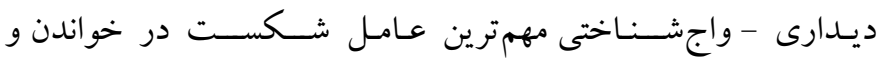


تشـكر و قدردانى: بدين وسيله از مسـولولان اداره آموزش و يرورش و كادر ادارى و

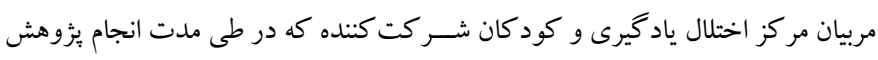

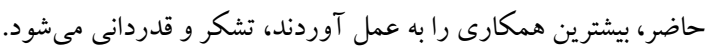

تضـاد منافع: انجام اين يروهش براى نو يسند گان هيج گونه تعارض منافع را به دنبال

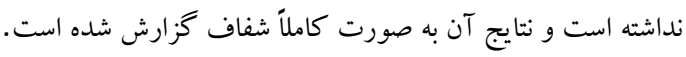




\section{References}

1. Semrud- clickman M. Neuropsychological Aspects for Evaluating Disabilities. Journal of Learning Disabilities. 2005; 38: 563-568. Doi: 10.1177 /00 22 2194050380061301 [Link]

2. American Psychiatric Association. Diagnostic and statistical manual of mental disorders. 5rd Edition. Washington, DC: APA; 2013, pp: 305-315. Doi: 10. 1176/appi.books.9780890425596 [Link]

3. Hallahan DP, Lloyd JW, Kauffman JM, Weiss MP, Martinez EA. Learning Disabilities: Foundations, Characteristics, and Effective Teaching. 3rd Edition. Pearson; 2005, pp: 21-25. [Link]

4. Eden GF, Olulade OA, Evans TM, Krafnick AJ, Alkire DR. Developmental Dyslexia. In: Small GHL, editor. Neurobiology of Language. San Diego: Academic Press; 2016, pp: 815-826. [Link]

5. Westwood P. What teachers need to know about reading and writing difficulties: Aust Council for $\mathrm{Ed}$ Research; 2008, pp: 39-48. [Link]

6. Reid G. Wearmouth J. Dyslexia and literacy: Theory and practice: John Wiley \& Sons; 2002, pp: 86-90. [Link]

7. Schwarb H, Nail J, Schumacher EH. Working memory training improves visual short-term memory capacity. Psychol Res, 2016; 80(1): 128-48. Doi: 10.1007/s00426-015-0648-y [Link]

8. Verhagen J, Leseman P. How do verbal short-term memory and working memory relate to the acquisition of vocabulary and grammar? A comparison between first and second language learners. J Exp Child Psychol. 2016; 141: 65-82. Doi: 10.1016/j.jecp. 20 15.06.015 [Link]

9. De Luca M, Burani C, Paizi D, Spinelli D, Zoccolotti P. Letter and letter string processing in developmental dyslexia. Cortex, 2010; 46: 1272-1283. Doi: 10. 101 6/j.cortex.2009.06.007 [Link]

10.Romani C, Tsouknida E, di Betta A. M, Olson A. Reduced attentional capacity, but normal processing speed and shifting of attention in developmental dyslexia: Evidence from a serial task. Cortex, 2011; 47: 715-733. Doi: 10.1016/j.cortex.2010.05.008 [Link]

11.Lerner J. Learning Disabilities Eleventh Edition Teachspace Web Booklet Forpackages. 11th Edition. Houghton Mifflin Company; 2008. [Link]

12.Sima Shirazi T, Moossavi A, Gholami Tehrani L, Hatamizadeh N, Rahgozar M, Ghelmanipoor M. Rapid naming in Persian children with dyslexia and its relation to reading level. Aud, 2014; 23(1): 10-20. [Persian]. [Link]

13. McBride-Chang C. Models of speech perception and phonological processing in reading. Child Development, 1996; 67, 1836-1856. Doi: 10.2307/ 1131735 [Link]

14.Torgensen JK, Mathes PG. A basic guide to understanding, assessing, and teaching phonological awareness. Austin, Tex: Pro-Ed, c; 2000, pp: 20-34. [Link]

15.Baezzat F, Moradi M, Motaghedifard M. The Effect of Phonological Awareness on the Auditory Memory in Students with Spelling Problems. Iranian Rehabilitation Journal. 2018; 16(1):83-90. Doi: 10.29 252/nrip.irj.16.1.83 [Persian]. [Link]

16. Hassanabadi H, Jesri N, Noury Ghasemabadi R. Visual Capacity versus Cognitive Process: Reducing Spelling Errors of Homophone Letters. Developmental Psychology: Iranian Psychologists, 2018; 14(55): 285-304. [Persian]. [Link]

17. Willburger E, Fussenegger B, Moll K, Wood G, Landerl, K. Naming speed in dyslexia and dyscalculia. Learn Ind Diff. 2008; 18(2): 224- 36. Doi: 10.101 6/j.lindif.2008.01.003 [Link]

18. Araújo S, Reis A, Petersson KM, Faísca L. Rapid automatized naming and reading performance: A meta-analysis. Journal of Educational Psychology. 2015; 107(3), 868-883. Doi: 10.1037/edu0000006 [Link]

19.Bexkens A. Wildenberg WP, Tijms J. Rapid automatized naming in children with dyslexia: Is inhibitory control involved?. Dyslexia. 2015; 21(3), 212-234. Doi: 10.1002/dys.1487 [Link]

20.Juul H, Poulsen M, Elbro C. Separating speed from accuracy in beginning reading development. Journal of Educational Psychology. 2014; 106(4), 1096-1106. Doi:10.1037/a0037100 [Link]

21.Fälth L, Gustafson S, Tjus T, Heimann M, Svensson I. Computer-assisted interventions targeting reading skills of children with readingdisabilities- A longitudinal study. Dyslexia Journal. 2013; 1199(11): 37-53. Doi:10.1037/a0037100 [Link]

22.Sohlberg MM, Mateer CA. Cognitive rehabilitation: An integrative neuropsychological approach. Guilford Publications; 2017, pp: 114-120. [Link]

23.Torman RK, Takala M. Auditory processing in developmental dyslexia: An exploratory study of an auditory and visual matching training program with Swedish children with developmental dyslexia. Health and Disability. Journal of Psychology. 2009; (50): 
277- 285. Doi: 10.1111/j.1467-9450.2009.00708.x. [Link]

24.Maehler C, Joerns C, Schuchardt K. Training Working Memory of Children with and without Dyslexia. Children (Basel). 2019; 6(3): 47-59. Doi: 10.3390/children6030047 [Link]

25.Shadbafi M, Khanjani Z. The Effectiveness of Treatment Based on Visual Stimulation in Reducing Spelling-Learning Disorder. Quarterly Journal of Child Mental Health. 2017; 4(2): 146-155. [Persian]. [Link]

26.Dahlin K.R.E. Effects of working memory training on reading in children with special needs. Read Writ, 2011; 24: 479-491. doi:10.1007/s11145-010-9238-y [Link]

27.Perebooma M, Peeters A, Overvelde A, Nijhuis-van der Sanden MWG, Steenbergen B. Learning of writing letter-like sequences in children with physical and multiple disabilities. Research in Developmental Disabilities, 2015; 36: 150-161. Doi: 10.1016/ j. ridd. 2014.10.005 [Link]

28. Chacko A, Uderman J, Feirsen N, Bedard AC, Marks D. Learning and Cognitive Disorders Multidiscipline Treatment Approaches. Child Adolesc Psychiatric Clin, 2013; 22: 457-477. [Link]

29. Blachman, B. A. Foundations of reading acquisition and dyslexia: Implications for early intervention: Routledge; 2013, pp: 1-488. Doi: 10.1016/ j.chc. 2013.03.006 [Link]

30. Website of the eth spin-off dybuster. [Link]

31. Shafiei B. Tavakol S. Alinia L. Maracy M. Sedaghati L. Foroughi R. Developing a screening inventory reading test (IRT) for the Isfahanian students of the first to fifth grade. Audiol, 2009; 17(2): 53-60. [Persian]. [Link]

32. Shahim S. Correlations for Wechsler Intelligence Scale for Children-Revised and the Wechsler Preschool and Primary Scale of Intelligence for Iranian Children. Psychological Reports, 1992; 70(1): 27-30. [Persian]. [Link]

33.Brock SE, Clinton A. Diagnosis of attention deficit/ hyperactivity disorder (AD/HD) in childhood: A Review of the literature. Child Dev.2007; (12): 73-91. Doi: 10.1007/BF03340933 [Link]

34. Shahaeian A, Shahim S, Bashash L, Yousefi F. Standardization, factor analysis and reliability Conners Rating Scale for children 6 to 11 years in Shiraz (Specially parents). Journal of Educational Psychology Studies. 2007; 3(3): 97-120. [Persian]. [Link]

35.Baezzat F. Validity and Reliability of the Preliminary Test of the Diagnostic Test of Written Disorders (Spelling) in the third to fifth grade elementary students of the third district of Tehran. Approved by the Deputy of Research and Technology of Shahid Beheshti University. Tehran; 2010. [Persian]. [Link]

36. Hosaini M, Moradi A, Kormi Nouri R, Hassani J, Parhoon H. Reliability and Validity of Reading and Dyslexia Test (NEMA). Advances in Cognitive Sceince. 2016; 18(1): 22-34. [Persian]. [Link]

37.Moradi A, Hosaini M, Kormi Nouri R, Hassani J, Parhoon H. Reliability and validity of reading and dyslexia test (NEMA). Advances in Cognitive Science. 2016; 18(1): 22-34. [Persian]. [Link] 